\title{
Geophysical examination of the 27 April 2016 Whakaari/White Island, New Zealand, eruption and its implications for vent physiognomies and eruptive dynamics
}

Braden Walsh ${ }^{1 *}$, Jonathan Procter ${ }^{1}$, Ivan Lokmer ${ }^{2}$, Johannes Thun ${ }^{3}$, Tony Hurst ${ }^{4}$, Bruce Christenson ${ }^{4}$ and Arthur Jolly 4

\begin{abstract}
At approximately 09:36 UTC on 27 April 2016, a phreatic eruption occurred on Whakaari Island (White Island) producing an eruption sequence that contained multiple eruptive pulses determined to have occurred over the first $30 \mathrm{~min}$, with a continuing tremor signal lasting $\sim 2 \mathrm{~h}$ after the pulsing sequence. To investigate the eruption dynamics, we used a combination of cross-correlation and coherence methods with acoustic data. To estimate locations for the eruptive pulses, seismic data were collected and eruption vent locations were inferred through the use of an amplitude source location method. We also investigated volcanic acoustic-seismic ratios for comparing inferred initiation depths of each pulse. Initial results show vent locations for the eruptive pulses were found to have possibly come from two separate locations only $\sim 50 \mathrm{~m}$ apart. These results compare favorably with acoustic lag time analysis. After error analysis, eruption sources are shown to conceivably come from a single vent, and differences in vent locations may not be constrained. Both vent location scenarios show that the eruption pulses gradually increase in strength with time, and that pulses 1, 3, 4, and 5 possibly came from a deeper source than pulses 2 and 6 . We show herein that the characteristics and locations of volcanic eruptions can be better understood through joint analysis combining data from several data sources.
\end{abstract}

Keywords: Amplitude source location, Infrasound, Source migration, Volcanic acoustic-seismic ratio, White Island

\section{Introduction}

Whakaari (Fig. 1) is an active volcanic composite cone that lies at the northern end of the Taupō Volcanic Zone in the Bay of Plenty, New Zealand (Houghton and Nairn 1991; Mayer et al. 2015). The island itself has a basal diameter of $\sim 17 \mathrm{~km}$, but only has about a $2.0 \mathrm{~km}$ diameter above the sea, and rises above sea level to $\sim 320 \mathrm{~m}$ in elevation (Houghton and Nairn 1991; Nishi et al. 1996). The horseshoe-shaped crater on Whakaari Island is a centrally located crater $\sim 0.5 \times 1.25 \mathrm{~km}$ in size, with the opening extending to the SW coastline, and lies up to

\footnotetext{
*Correspondence: B.Walsh@massey.ac.nz

${ }^{1}$ Volcanic Risk Solutions, Institute of Agriculture and Environment, Massey University, Private Bag 11 222, Palmerston North 4442, New Zealand Full list of author information is available at the end of the article
}

$10 \mathrm{~m}$ below sea level (Nishi et al. 1996). Periodically, the active crater fills up with a combination of seawater, rainwater, and volcanic vapors, hiding the active vent location (Christenson et al. 2017).

The existence of water has given Whakaari many periods of continuous hydrothermal activity, with sporadic phreatic eruptions as well as phreatomagmatic and Strombolian eruptions (Nishi et al. 1996; Cole et al. 2000; Mayer et al. 2015). It is inferred that these eruptions originate at shallow depths $(<1.0 \mathrm{~km})$ (i.e., Nishi et al. 1996; Jolly et al. 2017a) due to the theorized location (0.5-2.0 km in depth) of the magma chamber in the upper crust (Houghton and Nairn 1991; Cole et al. 2000; Werner et al. 2008). The hydrothermal activity sourced from these shallow depths is expressed on the surface during non-eruptive periods as intense degassing 


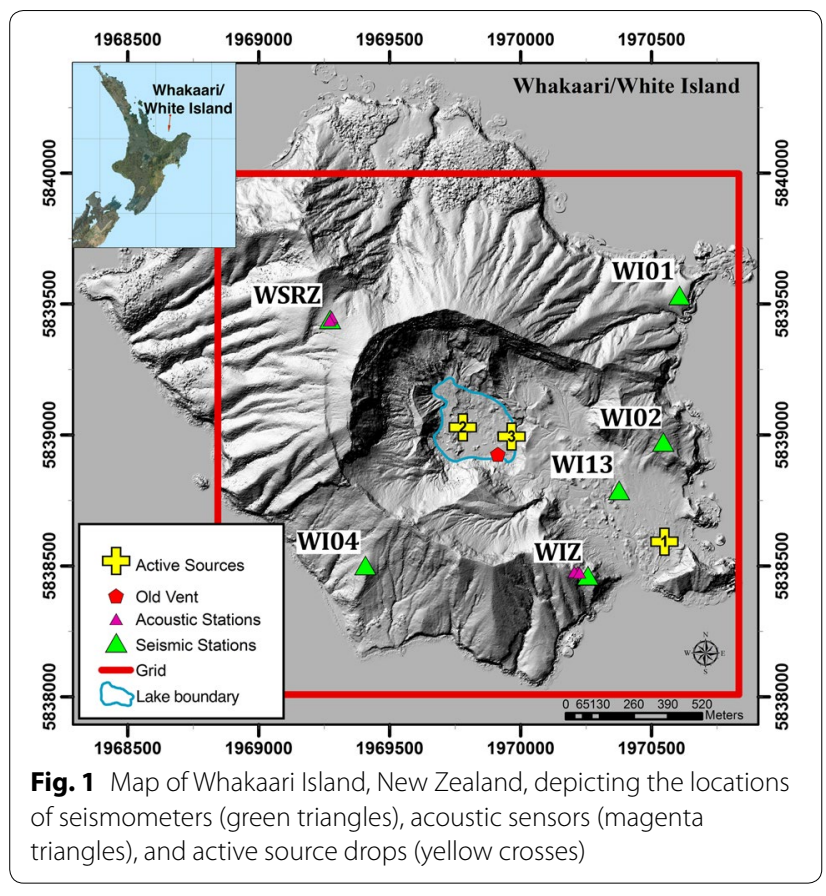

fumaroles, mud bubbles, steaming ground, and hot springs (Houghton and Nairn 1991; Heap et al. 2015).

The first seismometer (WIZ) was installed on Whakaari in 1976 and began recording many different types of earthquakes (Sherburn et al. 1998). In 2007, the seismic station was upgraded to a broadband sensor, but it was not until 2013 that a second recording station (WSRZ) was installed. However, since 2011 Geological and Nuclear Sciences (GNS) has operated a varying number of seismic stations, which has led to modern volcanic monitoring. Subsequently, ever since seismometers have been installed on the island, many have described in detail the different types of signals produced by the Whakaari volcanic system: volcano-tectonic (VT) events (Nishi et al. 1996), long-period (LP) events (Sherburn and Scott 1993), very long-period (VLP) events (Jolly et al. 2017a), and volcanic tremor (Sherburn et al. 1991).

A source location for an event is one of the most important parameters in risk management and hazard analysis. This significance has led to the development and advancement of many source location techniques. Source location methods are typically divided up into four categories depending on event type, recording network, and the properties of the recorded waveforms. Arrival time methods (e.g., Lee et al. 1972; Lahr 1989) are mostly used for brittle rock failures that have well-defined onsets (e.g., teleseismic earthquakes). Many have tried using these methods in regard to volcanoes with some success (e.g., Lahr et al. 1994; Aspinall et al. 1998), but a plethora of assumptions and corrections was used. For instance, long-period earthquakes from slow rupture or resonance may have weak or absent S-phases making the S-arrivals difficult to find among the late arrivals. On the other hand, the P- and S-arrivals of volcano-tectonic earthquakes have more impulsive amplitudes than LP events, which make the phases slightly easier to distinguish (Lahr et al. 1994). Another problem that arises in volcanic settings is the heterogeneities of the geological structure (Jolly et al. 2014b). Nonlinear, poorly known velocity models can cause travel-time determinations to be difficult due to weak or emergent arrival times especially in the S-phase (Lahr et al. 1994). Furthermore, arrival picks can be difficult when signals are weak or if there are continually arriving excitations (i.e., tremor).

Coherence methods (e.g., semblance, back projection, etc.) locate a source from a signal by finding coherency. The semblance method (e.g., Neidel and Tarner 1971; Almendros and Chouet 2003) is based on normalizing the ratio of the sum of the traces by each individual trace, then cross-correlating them. Semblance is very useful when waveforms are at low frequencies (e.g., Almendros and Chouet 2003), hence their utility in locating sources of different volcanic events such as LP events (Chouet et al. 1999) and very long-period events (Kawakatsu et al. 2000; Nishimura et al. 2000). However, semblance does lack in accuracy when locating higher-frequency content or waveforms with large amounts of noise. Due to the effectiveness of semblance and other coherence methods at low frequencies, they have become reliable to use with acoustic monitoring as well (e.g., Ripepe and Marchetti 2002; Garcés et al. 2003; Johnson et al. 2006). Another popular coherence method is back projection (e.g., Ishii et al. 2005). Back projection is based on the reverse-time migration technique used for reflection seismology and has the advantage of not needing a priori information about the event (Ishii et al. 2007). Like semblance, back projection looks at waveform similarities across multiple stations by normalizing and stacking them, which can then can be used with a search technique (e.g., grid search) to locate the source (Ishii et al. 2005). Back projection can also be applied to acoustic data for locating acoustic sources (e.g., Jolly et al. 2014a). The drawback to back projection is that this method requires the energy release of the source to be time independent. If the release of energy is highly time dependent, it can create artifacts from higher energies, which can overpower and conceal the lower energy signals (Ishii 2011).

The amplitude source location (ASL) method (e.g., Kanamori 1993; Yamasato 1997) is used for finding many different event source locations due to its ability to locate sources in areas where more traditional methods fail. ASL exploits the decay of the amplitude through geometrical spreading and attenuation of the waveform to estimate an 
original amplitude and source location (see ASL section below). Furthermore, along with traditional ASL, recently the active source matching method has been able to estimate source locations with great accuracy (e.g., Jolly et al. 2014a; Walsh et al. 2016). The method compares the decay characteristics with that of the natural event, avoiding the need for site and path assumptions. Another advantage is the ability to estimate the energy of an event with time by comparing the energy of the active sources with the event along a path (e.g., mass flows in a channel). The active source method is lacking when it comes to the likelihood of having conducted an active source experiment at the site of interest, and locating sources at depth when using surface sources. Additionally, results can only be as precise as the number of active sources used, the resolution of sources, and can only fall within the same frequency range of the active sources (Jolly et al. 2014b).

Here, we will use a combination of both seismic and acoustic data to characterize the eruption sequence on 27 April 2016. An ASL technique is used to locate eruption vents by a combination of using the non-corrected ASL approach, in tandem with calibrating the path and site effects through the use of active seismic sources. Acoustic data are used to estimate the precise timing and properties of the eruption through the use of standard methods (e.g., migration, coherence, etc.). Finally, the acoustic and seismic data are compared using a volcanic acoustic-seismic ratio to estimate eruption characteristics. Furthermore, we examine our results for vent locations with multiple error analyses and provide possible outcomes of eruption dynamics.

\section{Data}

During the April 2016 eruption, there were two permanent GeoNet seismic stations (WIZ and WSRZ), along with four GNS Science seismic stations (WI01, WI02, WI04, and WI13) (Fig. 1). The GeoNet seismic stations consisted of Guralp 3ESP broadband seismometers with a Quanterra Q330 digitizer. The GNS stations were composed of both Trillium compact seismometers and 24-bit Nanometrics Taurus digitizers. Furthermore, sites WIZ and WSRZ contained three acoustic sensors, one Setra 270-600 pressure transducer and two InfraBSU sensors with a sensitivity of $42 \mathrm{mV} / \mathrm{Pa}$. The acoustic sensors on Whakaari are set up in two sets of "L"-shaped arrays, where the distances between sensors could only range between 5 and $15 \mathrm{~m}$ due to topographical boundaries. Both seismic and acoustic instruments at every recording site sampled at $100 \mathrm{~Hz}$.

\section{Eruption history and background}

On 27 April 2016 at 09:30 UTC, a moderate-sized phreatic eruption occurred during the night, which ejected the entire crater lake along with a considerable amount of ash and debris that deposited on and around Whakaari. The eruption contained no juvenile material and only redeposited the crater floor material (Kilgour et al. 2019, this issue). Furthermore, Hamling (2017) used InSAR to discover that the eruption was preceded by a period of uplift. Using line-of-sight measurements Hamling (2017) recorded motions on the island ranging between 10 and $50 \mathrm{~mm} /$ year from June 2015 up until the time of eruption. The eruptive plume reached a maximum height of $4.0 \mathrm{~km}$ and covered the entire island with dark yellowgreen ash. The ash thickness was $5.0 \mathrm{~mm}$ at a distance of $\sim 500 \mathrm{~m}$ from the eruption vent (Kilgour et al. 2019, this issue). Along with ash deposits, surge deposits were found along the eastern side of the crater. The surge deposits are thought to have been ejected horizontally, since the deposits were only found on one side of large objects such as boulders (Kilgour et al. 2019, this issue). After the eruption, ground displacement rates around the crater increased by $300 \%$ due to the instability brought on by the expulsion of water in the crater lake. This led to the partial collapse of the crater rim causing material to start propagating down slope (Hamling 2017).

The eruption event can be characterized as an eruptive sequence of up to six distinct pulses occurring over the first $30 \mathrm{~min}$, and a late tremor sequence lasting up to $2 \mathrm{~h}$ after the pulsing phase. Both seismic (Fig. 2) and acoustic (Figs. 3, 4) sensors on the island were able to record these events. The eruptive pulses each lasted $\sim 1$ to $2 \mathrm{~min}$ in length and were separated on average of $\sim 7.0 \mathrm{~min}$ apart. Additionally, the seismic data recorded a VLP earthquake that preceded the fourth eruptive pulse and the most energetic portion of the eruption at 09:53 UTC.

\section{Locating eruption sources using the amplitude source location method}

The amplitude source location method uses the theory of seismic waves decaying with distance due to intrinsic attenuation and geometrical spreading to estimate an original amplitude (Yamasato 1997). Many have since used ASL to estimate locations from a variety of sources, such as debris flows (Ogiso and Yomogida 2015), lahars (Kumagai et al. 2009), pyroclastic flows (Yamasato 1997), rockfalls (Aki and Ferrazzini 2000), VT earthquakes (Kumagai et al. 2013), volcanic tremor (Ogiso et al. 2015), LP events (Battaglia and Aki 2003), explosion events (Kumagai et al. 2011), and magma intrusions (Taisne et al. 2011).

Here, we follow the method proposed by Battaglia and Aki (2003), who were among the first to apply ASL to volcanic processes and Walsh et al. (2017) to estimate the locations of the six main eruptive pulses of the 27 April 

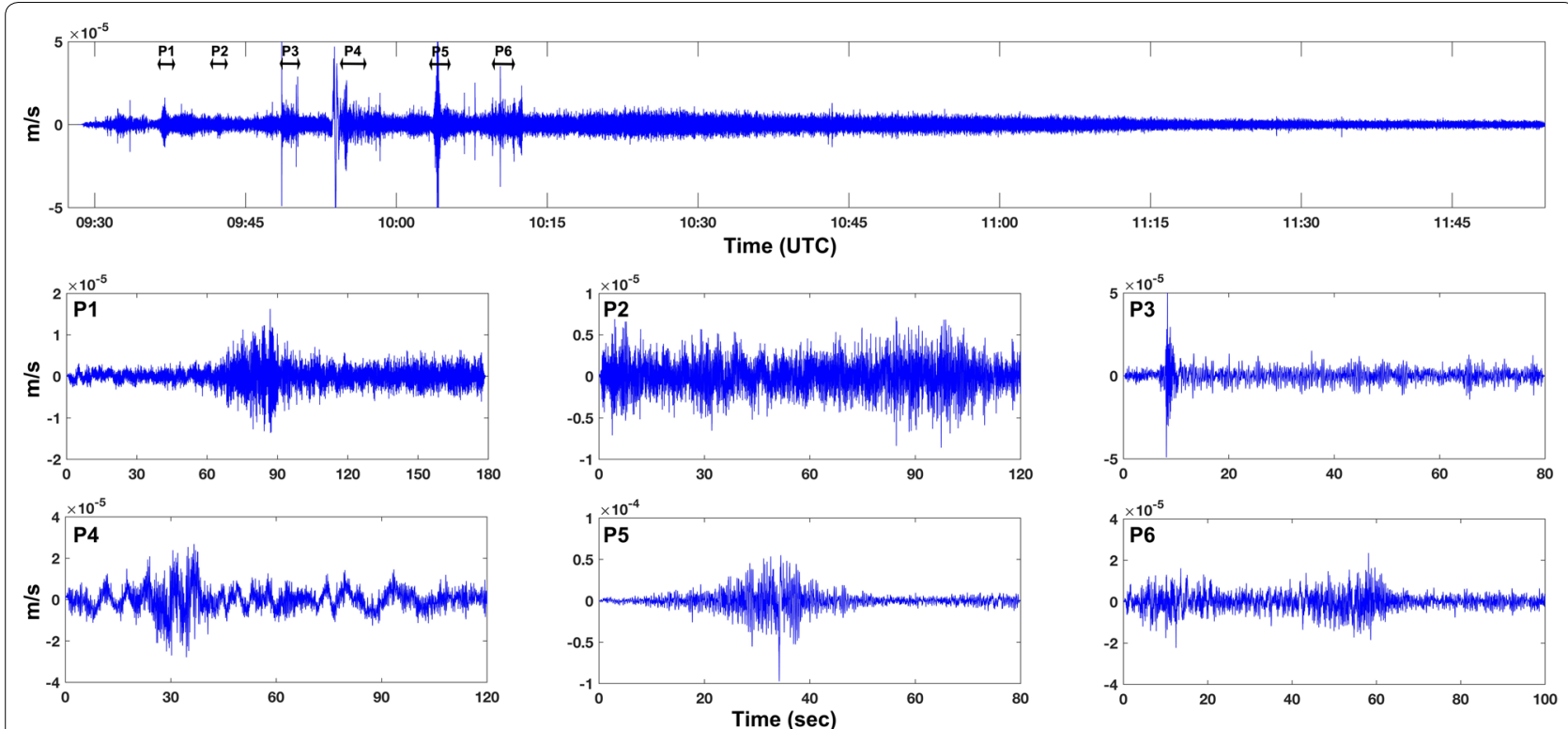

Fig. 2 Seismic waveforms (no filter) from station WIZ of the 27 April 2016 Whakaari eruption. Eruption pulses are shown in time by black arrows. Subfigures represent each of the eruptive pulses during the event

2016 Whakaari event. Seismic wave decay for a body wave is represented by:

$$
A=A_{0} \frac{e^{-B \cdot r}}{r} \cdot S
$$

where $A$ is the observed amplitude, $r$ is the distance between the source and receiver, $S$ is the site amplification correction, and $B$ is the attenuation factor described as:

$$
B=\frac{\pi f}{Q \beta}
$$

where $f$ is the average frequency of the signal (e.g., $7.5 \mathrm{~Hz}$ for a signal filtered between 5 and $10 \mathrm{~Hz}$ ), $Q$ is the quality factor, and $\beta$ is the average $\mathrm{S}$-wave velocity. Rearranging Eq. (1) to solve for the original amplitude, we get:

$$
A_{0}=\frac{1}{N} \sum_{i=1}^{N} \frac{A_{i}}{S_{i}} r_{i} e^{B r_{i}}
$$

where $N$ is the total number of seismic stations and $i$ is a single station. Knowing both observed amplitude and estimated original amplitudes, we can then calculate errors by determining normalized residuals by:

$$
\text { Residual Error } \equiv \frac{\sum_{i=1}^{N}\left[A_{i}-A_{0} \frac{e^{-B r_{i}}}{r_{i}}\right]^{2}}{\sum_{i=1}^{N} A_{i}^{2}}
$$

To perform ASL, a grid search is used to estimate $A_{0}$ using Eq. (3) at each grid point. After $A_{0}$ is calculated, Eq. (4) is used to estimate a residual error for every point in the grid. Next, the grid point with the minimum residual error is used as the predicted most likely ASL of the source. At Whakaari, we use an ASL grid $2 \times 2 \mathrm{~km}$ in area with $10 \mathrm{~m}$ grid spacing between each point where topography is also considered by assigning an elevation value to each grid point for the analysis. We use a topographical surface grid because while excitations are likely to extend below the active vent region, we are only focusing on the seismic signals that are coincident with the acoustic eruption periods, and thus, we assess that the source is constrained to the surface.

For the ASL method to work, multiple input parameters are needed to make use of Eqs. (1-4). First, we note that, for our location results, we do not calculate site amplification. Others have shown at various other locations that amplification corrections are not necessary to achieve reliable location results, most notably on Tungurahua, Ecuador (Kumagai et al. 2015), Te Maari, New Zealand (Walsh et al. 2017), and Illgraben, Switzerland (Walter et al. 2017).

To estimate eruption locations, the frequency range of 5-10 Hz was used, which is consistent with previous ASL research and well within the peak energy range of the 27 April eruption (Fig. 5). Even though Fig. 5 shows a reasonable amount of energy below $5 \mathrm{~Hz}$, we note that using the ASL method in these frequency ranges can alter location results because of the non-homogeneous radiation 

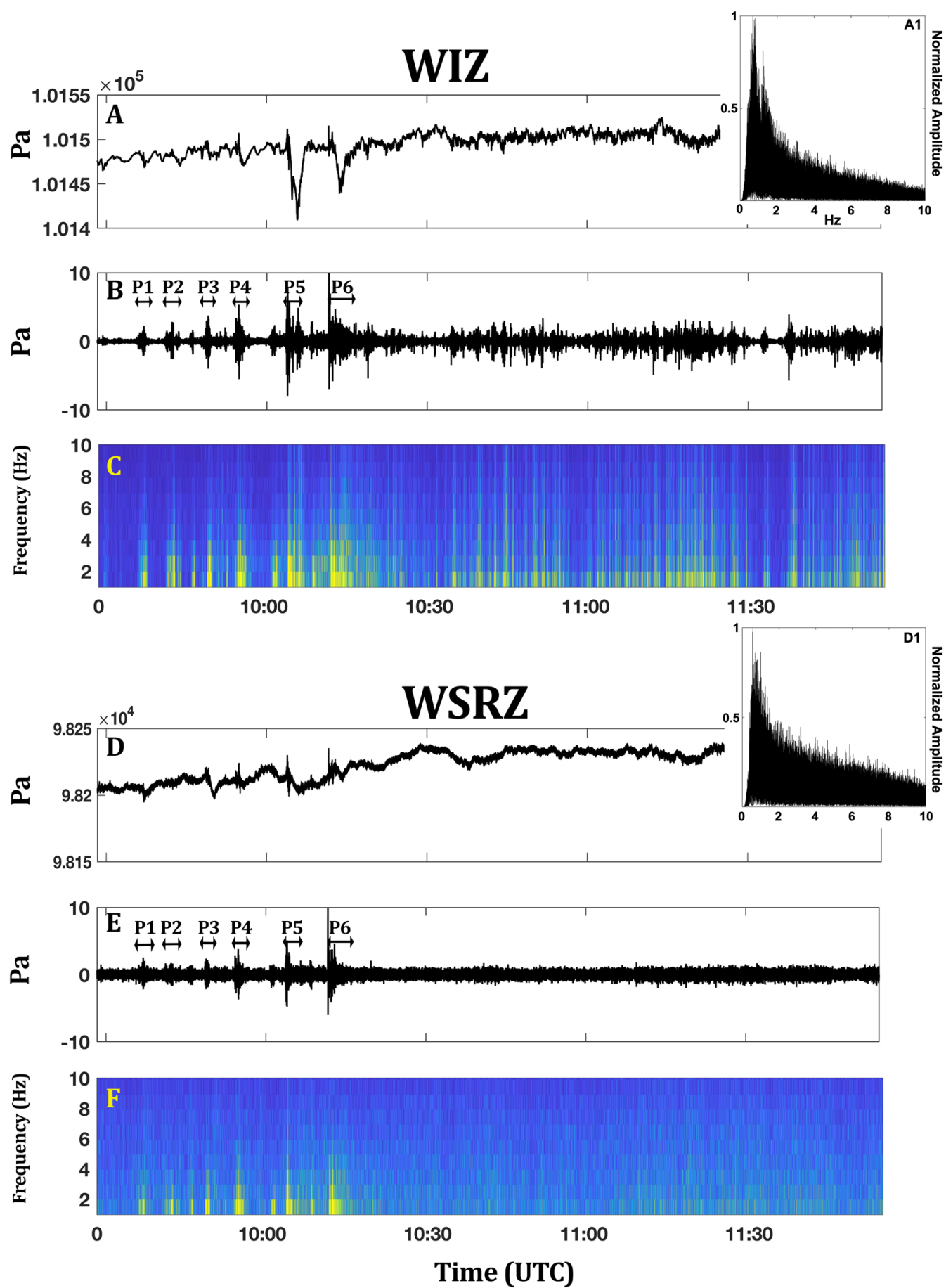

Fig. 3 Acoustic waveform data for both acoustic stations for the 27 April 2016 eruption on Whakaari. A Non-filtered raw sensor reading for WIZ showing the increasingly larger down pressures from the rarefaction of the eruption pulses as the acoustic wave passes the station. $\mathbf{B}$ Filtered acoustic data between 0.5 and $10 \mathrm{~Hz}, \mathbf{C}$ spectrogram for WIZ, D non-filtered raw sensor reading for WSRZ, E filtered acoustic data between 0.5 and $10 \mathrm{~Hz}$ for WSRZ, F eruption spectrogram for WSRZ. A1 and $\mathbf{D} \mathbf{1}$ are the spectra for WIZ and WSRZ respectively

patterns below $5 \mathrm{~Hz}$ (Takemura et al. 2009). Due to tremor occurring during the time gaps between eruptive pulses, the eruption spectra (Fig. 4, black signals) display some pre-event characteristics. Baseline parameters for the ASL grid search include an S-wave velocity of $1300 \mathrm{~m} / \mathrm{s}$ (Jolly et al. 2017a, b) and a quality factor 


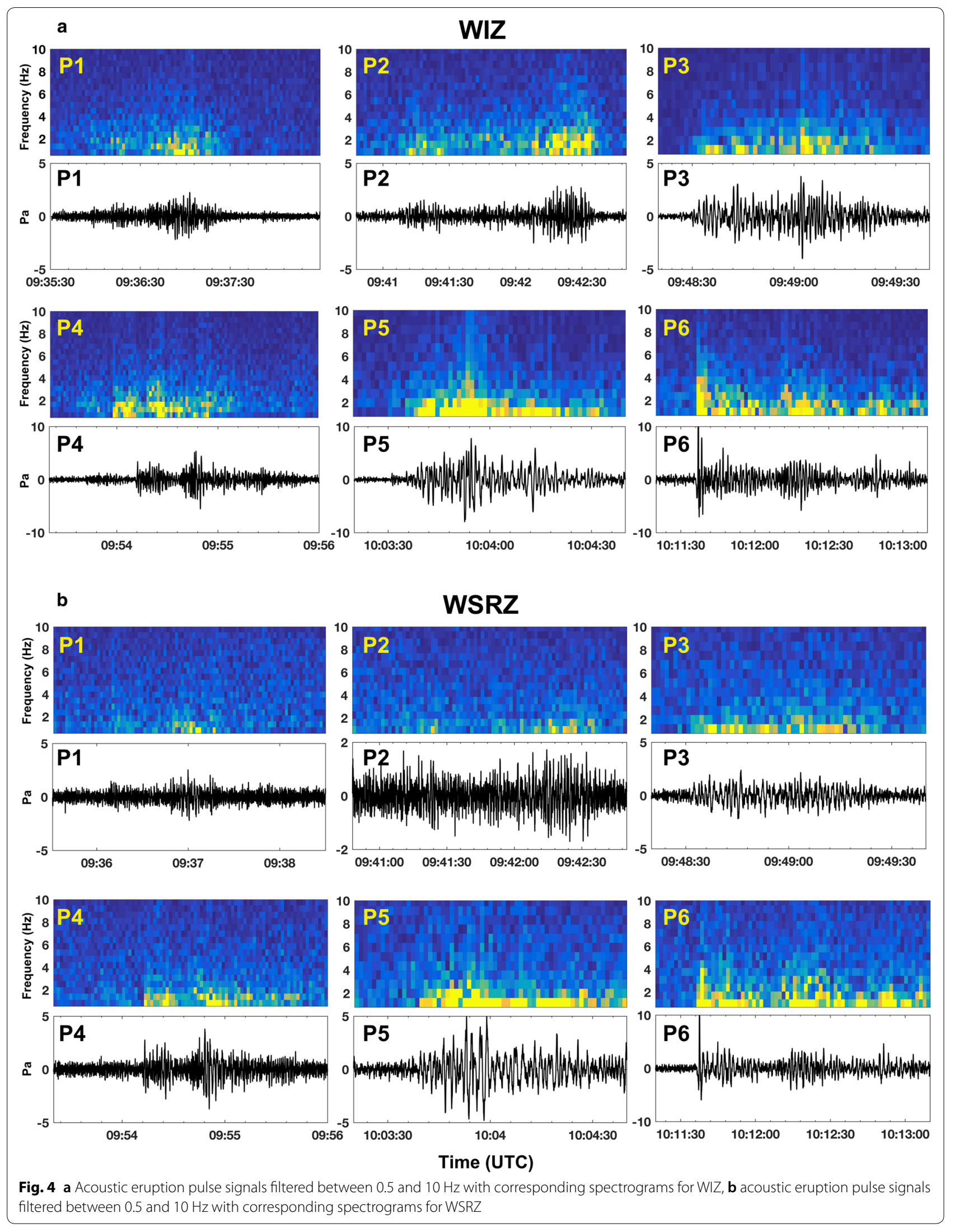




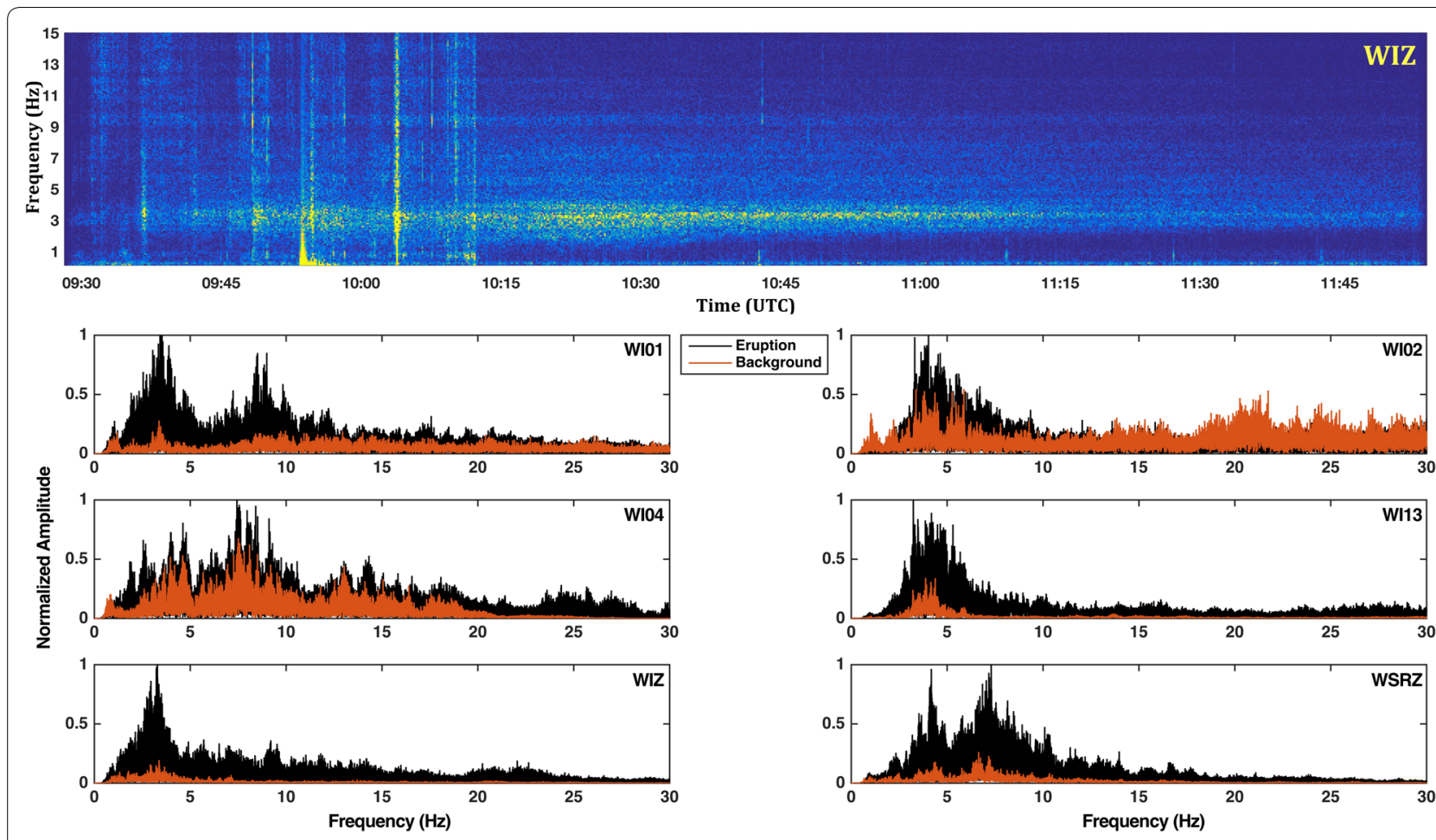

Fig. 5 Seismic spectrogram for the eruption event (station WIZ) along with amplitude spectra for each of the seismic stations. The eruption spectra (black) are overlain by pre-event noise (orange) for background noise comparison

of $Q=10$ (Jolly et al. 2012) for all subsequent analyses except where indicated.

Location results for the six pulses were obtained (Fig. 6) from the vertical waveforms using the baseline input parameters. Stars represent the ASL minimal residual error location for the particular eruptive pulse. Lighter shades represent earlier pulses, and darker shades represent later arriving pulses. Pulses 1,4 , and 5 plot at the same location, whereas pulses 2,3 , and 6 are altogether to the Northwest of the crater. The ASL locations are $\sim 400$ to $500 \mathrm{~m}$ off from the theorized vent location as well, not locating in the crater lake. The lowest residual locations instead plot up on the steep crater slope; thus, more investigations need to be conducted on input values in addition to site and path corrections. We also estimated locations based on surface wave velocities (results not shown) to investigate if they would provide more reliable results. Using surface waves for the ASL method produced similar location errors to that of the body wave results.

To examine the input parameters on the ASL results, we next assess the sensitivity of the ASL method by changing the velocity and attenuation of the medium for each pulse (Fig. 7). For all of the pulses, the minimal residual error ASL after sensitivity analysis changes up to $\mathrm{a} \sim 300 \mathrm{~m}$ difference. Increasing the quality factor

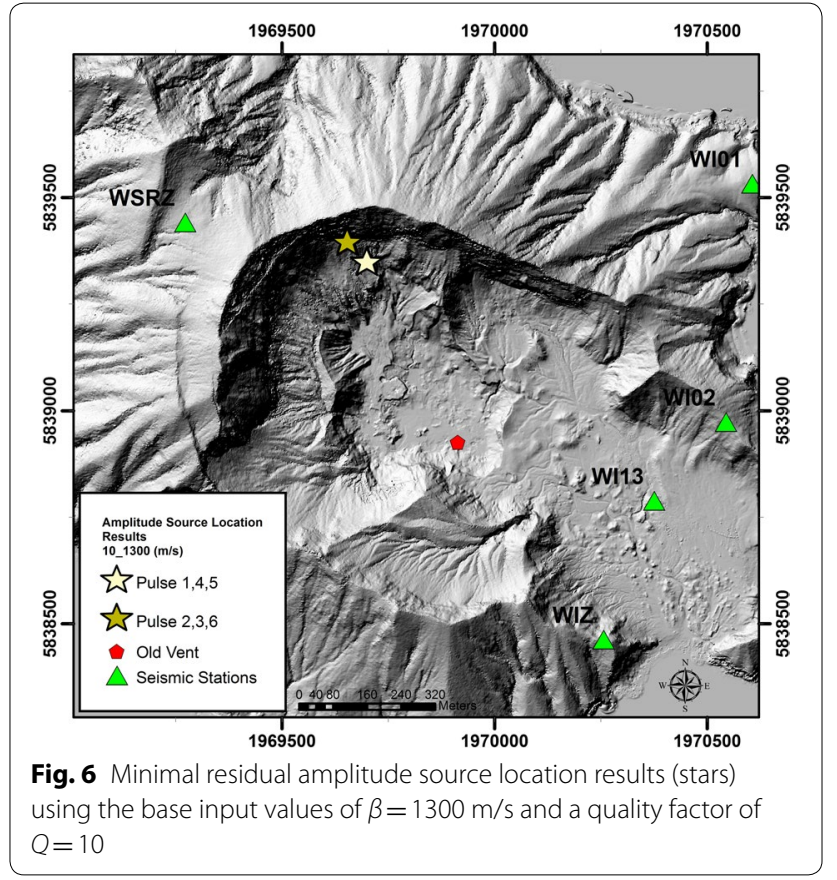

moves the minimal residual location to the Northwest, while decreasing the quality factor moves the location to the Southeast toward the active crater. Increasing and 

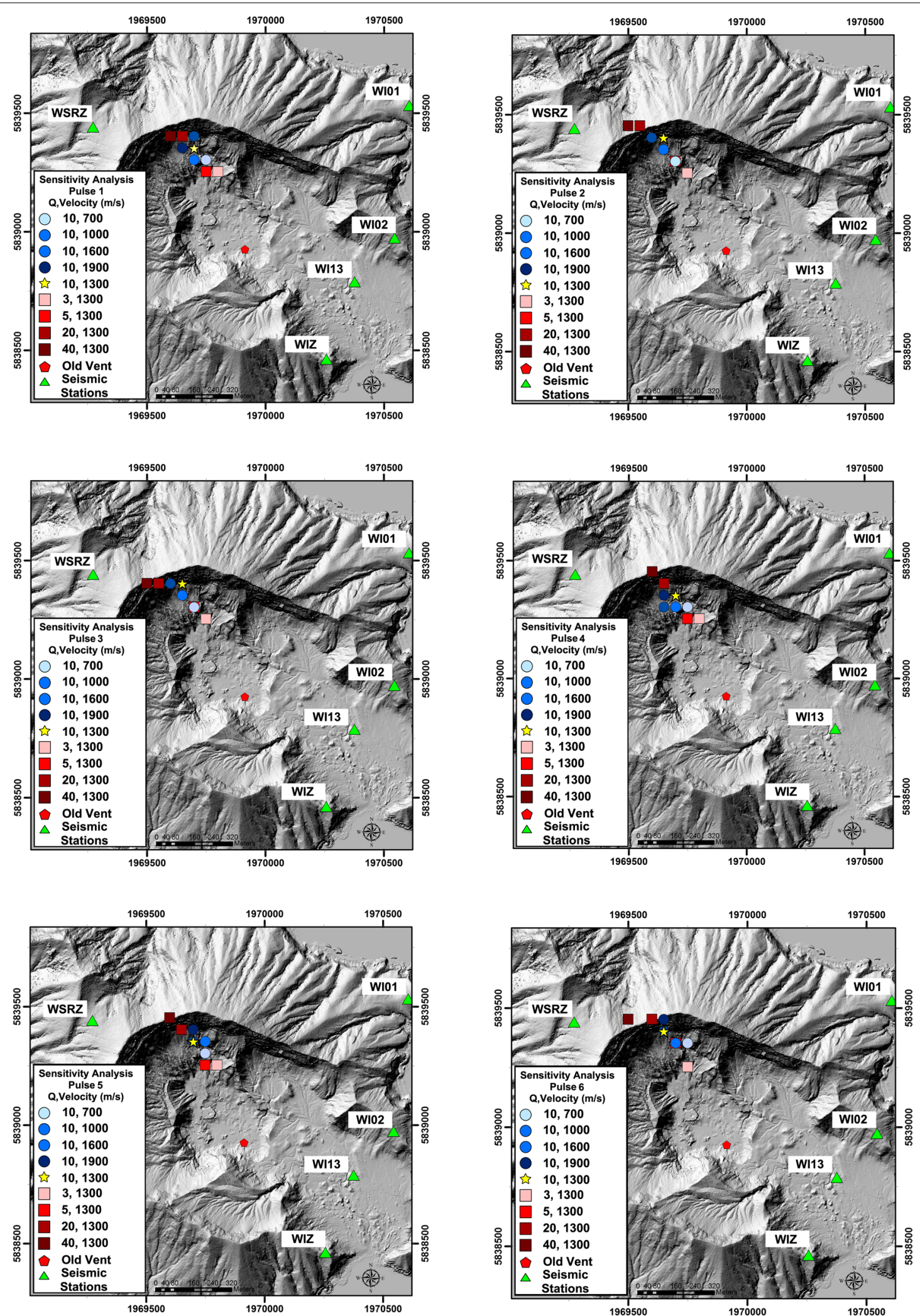

Fig. 7 Amplitude source location results for each of the eruptive pulses with variable attenuation and velocity. The stars represent the base values of a $Q=10$ and a body wave velocity of $\beta=1300 \mathrm{~m} / \mathrm{s}$, while the changing attenuation values are represented as squares and the velocity as circles 
decreasing the velocity input produces the same results displaying the theoretical trade-off between the two values shown in Eq. (2). Examining all six pulses, inputs of a quality factor of $Q=3$ and a velocity of $1300 \mathrm{~m} / \mathrm{s}$ show the best locations compared to the theorized vent location. The very strong attenuation $(Q=3)$ value used in obtaining improved results is consistent with a prior active source experiment on Whakaari (Jolly et al. 2012).

With the best predicted ASL results (Fig. 8 pink stars) locating on average a couple hundred meters away from the estimated vent location, we next follow Walsh et al. (2017) by calibrating the ASL locations. Instead of calculating amplification factors, active source events (Jolly et al. 2012) are used to correct source and path effects. In 2011, three large $700 \mathrm{~kg}$ bags of beach sand were dropped $\sim 300$ to $400 \mathrm{~m}$ above ground height. The first impact location was located by GPS, whereas the next two impact locations were located by triangulation. The sand bag impacts were recorded on 15 3-component broadband seismic stations on Whakaari. To process the active source data, the impacts arrivals were picked, had instrument responses removed, were placed under a $1 \%$ Hanning taper, and finally filtered between 5 and $10 \mathrm{~Hz}$ for use with the natural data for the determination of station corrections on Whakaari (Table 1). Two of the three active source events landed in the active crater, with a third locating beyond station WI13 (Fig. 1), and not centrally located. Subsequently, due to active source

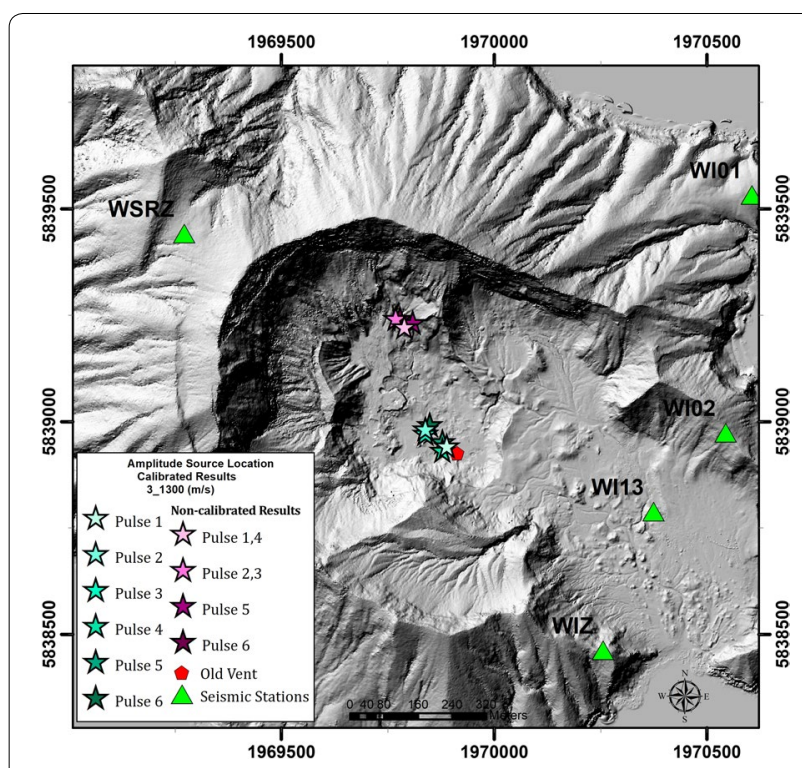

Fig. 8 Calibrated amplitude source location results for each eruption pulse. Input values of a quality factor of $Q=3$ and a body wave velocity of $\beta=1300 \mathrm{~m} / \mathrm{s}$ were used to estimate the locations of non-calibrated results (pink stars) and active source calibrated locations (green stars)
Table 1 Station corrections estimated from active sources for 15 broadband seismometers that were installed during the active source experiment

\begin{tabular}{lcl}
\hline Station & Station corrections & $\begin{array}{l}\text { Standard } \\
\text { deviation }\end{array}$ \\
\hline WI01 & 8.209 & 1.649 \\
WI02 & 3.596 & 0.825 \\
WI03 & 38.841 & 13.477 \\
WI04 & 2.457 & 0.549 \\
WI05 & 20.083 & 8.946 \\
WI06 & 47.797 & 39.832 \\
WI08 & 16.114 & 11.781 \\
WI09 & 4.974 & 3.954 \\
WI10 & 4.214 & 2.833 \\
WI12 & 9.798 & 1.075 \\
WI13 & 1.828 & 0.198 \\
WI14 & 0.264 & 0.012 \\
WI15 & 0.545 & 0.238 \\
WIZ & 1 & NA \\
WSRZ & 23.334 & 18.532 \\
\hline
\end{tabular}

locations, we only use the two events that located in the crater to estimate station corrections.

After calibrating the ASL method from active source events on Whakaari, location estimates for eruptive pulses (Fig. 8, green stars) locate on or close to the inferred vent location. The calibration of the ASL yielded a direct distance difference of $\sim 300 \mathrm{~m}$ from the best located non-corrected results (Fig. 8, pink stars). Likewise, the estimated calibrated pulse locations similarly locate together like the original results, where pulses 1 , 4 , and 5 , and 2, 3, and 6 are grouped together. The groupings may not have any significance because like the original results, the group locations are only $\sim 0 \mathrm{~m}$ apart from one another (see error analysis in discussion). This close proximity may also indicate a non-vertical conduit, at which the minimal residual location may be indicating the location where the elastic energy couples to the earth (e.g., Chouet et al. 2010), where pulses 1, 4, 5 are coupling further down the inclined conduit than pulses 2, 3, and 6 giving the illusion of two possible separate eruption vents (see VASR section below).

\section{Insights into eruption dynamics using infrasound}

The characteristics of the eruption, more specifically the individual eruptive pulses, will be examined next via the acoustic waveform data in order to further the investigation. Acoustic data have been used for many years on and around volcanoes to understand eruptive behavior (e.g., Vergniolle and Brandeis 1994; Yamasato 1997; Johnson 2003). Acoustic data from volcanoes are relatively 
easy to record because when a volcano erupts, it causes an increased pressure trace relative to the atmospheric background (Johnson 2003). Additionally, acoustic signals given off by eruptions tend to be dominated by frequencies below $10 \mathrm{~Hz}$ (e.g., Garcés and McNutt 1997; Ripepe and Marchetti 2002; Jones et al. 2008).

The April 2016 eruption has shown similar traits, most notably in the low-frequency content (Fig. 3). The peak frequency range of the eruption is under $\sim 5.0 \mathrm{~Hz}$ (Fig. 3c, f) and is the strongest during the six eruptive pulse phases. Figure 3 also shows the raw unfiltered acoustic signal for stations WIZ (Fig. 3a) and WSRZ (Fig. 3d), as well as, the acoustic signal filtered between 0.5 and $10 \mathrm{~Hz}$ (Fig. 3b, e) for better representation of the pulses and timing. Even though the infrasonic tremor sequence after the eruptive pulse phase contains some minor pulses and peaks, the frequency strength does not show any difference to the background noise, indicating that there most likely were no more surface events after the initial pulse phase.

To further investigate the acoustic data from the April 2016 Whakaari eruption, each pulse was extracted out of the greater signal and plotted on its own (Fig. 4). Along with each acoustic pulse signal, we also create an unfiltered spectrogram for each eruption pulse (Fig. 4, top rows). The frequency content of each pulse is very similar in that the frequency range is all below $\sim 5.0 \mathrm{~Hz}$. While all the pulses depict similar frequency ranges, the differences of the spectral content in each pulse lie within the variable frequencies through the duration of each individual pulse. These frequency characteristics have been recorded on Whakaari previously when Jolly et al. (2016) recorded mud bubble bursts from within the crater on the island. They also noted that station WIZ had higherfrequency peaks than that of WSRZ, which also can be seen for the pulses in Figs. 3 and 4 for the April 2016 eruption.

At Whakaari, due to the dimensions of the acoustic sensor setup and distance to the active vents/crater $(<1.0 \mathrm{~km})$, traditional volcano acoustic method results are not the most reliable and accurate. The sensor spacing range of 5-15 m limits the range of frequency content that can be distinguished between each of the three sensors in the array. To this extent, location methods such as back projection (e.g., Jolly et al. 2014b) cannot provide reliable results either, due to the insignificant travel-time variations and poor station distribution. Therefore, with this instrumental set up, we only use the Setra acoustic sensors from each station location, and estimate lag times, correlation, and coherence (Fig. 9) for the eruption (e.g., Ichihara et al. 2012; Matoza and Fee 2014). To create Fig. 9, we used unfiltered data and calculated the correlation and coherence at 10-s time windows. In estimating the coherence, we use the magnitude-squared approach that can be described as:

$$
\gamma_{12}^{2}=\frac{\left|S_{12}\right|^{2}}{S_{11} S_{22}}
$$

where $S_{11}$ and $S_{22}$ are the power spectra from each of the two acoustic stations, and $S_{12}$ is the cross-spectrum. To compare the coherence and lag times with the eruption, we also overlaid both acoustic signals (Fig. 9C). In Fig. 9C, station WIZ (blue) records the eruption onsets of each pulse first followed by WSRZ (red). The lag times between the two stations (Fig. 9A) are strongly correlated to the timing of higher coherence (Fig. 9B) during the
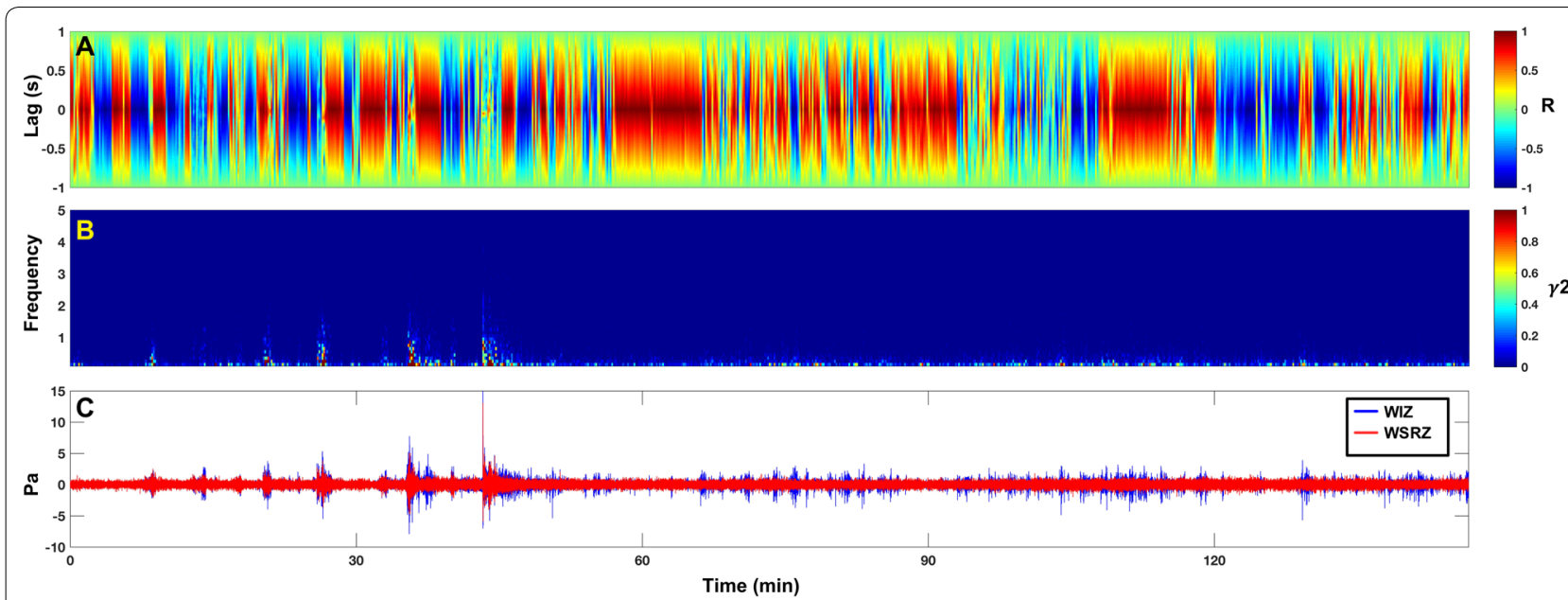

Fig. 9 Acoustic time evolution comparing station WIZ with WSRZ of the 27 April 2016 eruption. A Unfiltered cross-correlation, B unfiltered coherence, $\mathbf{C}$ acoustic signals WIZ and WSRZ overlain filtered between 0.5 and $10 \mathrm{~Hz}$. Subfigures $\mathbf{A}$ and $\mathbf{B}$ were estimated from 10 -s moving time windows 
eruption. When there is an increase in coherence during the eruption phase, the correlation with lag significantly changes (see time periods of eruptive pulses). To get a better understanding of the relationship between the coherence and lag times, we next show the same plot, but this time for each individual pulse, and at 5-s running time windows (Fig. 10). For each pulse, the lag times between the stations are not consistent, but the highest correlated lags are all between about -0.25 and $0.25 \mathrm{~s}$, suggesting that the pulses may have come from the same general area of the crater. As expected, during time widows of low or no coherence, there is also very
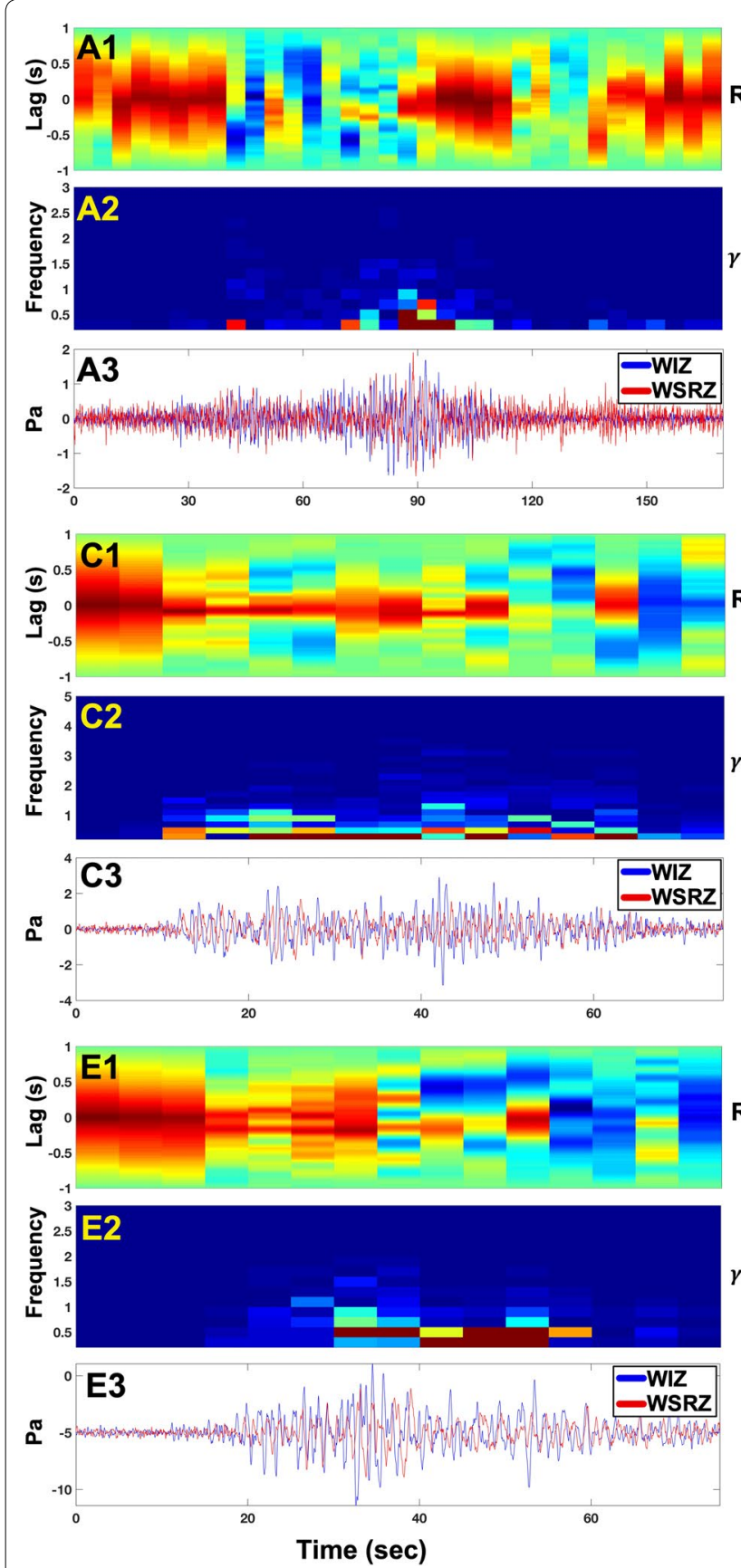

$\mathbf{R} \begin{array}{lr}\mathbf{1} & 1 \\ \mathbf{0 . 5} & 0.5 \\ \mathbf{0} & 0 \\ -0.5 & 0.5 \\ -1 & -1\end{array}$
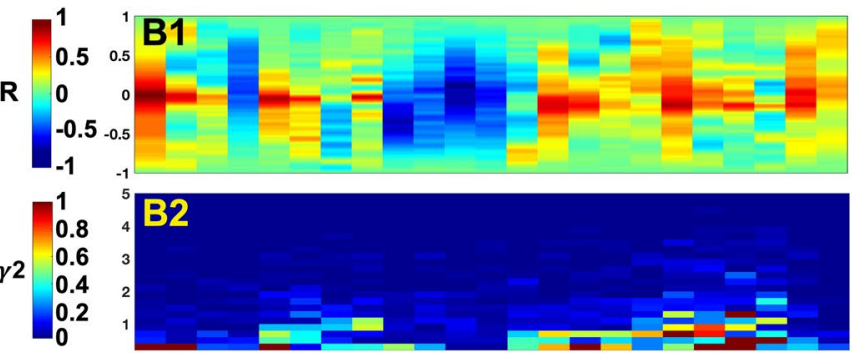

${ }^{4}$ B3
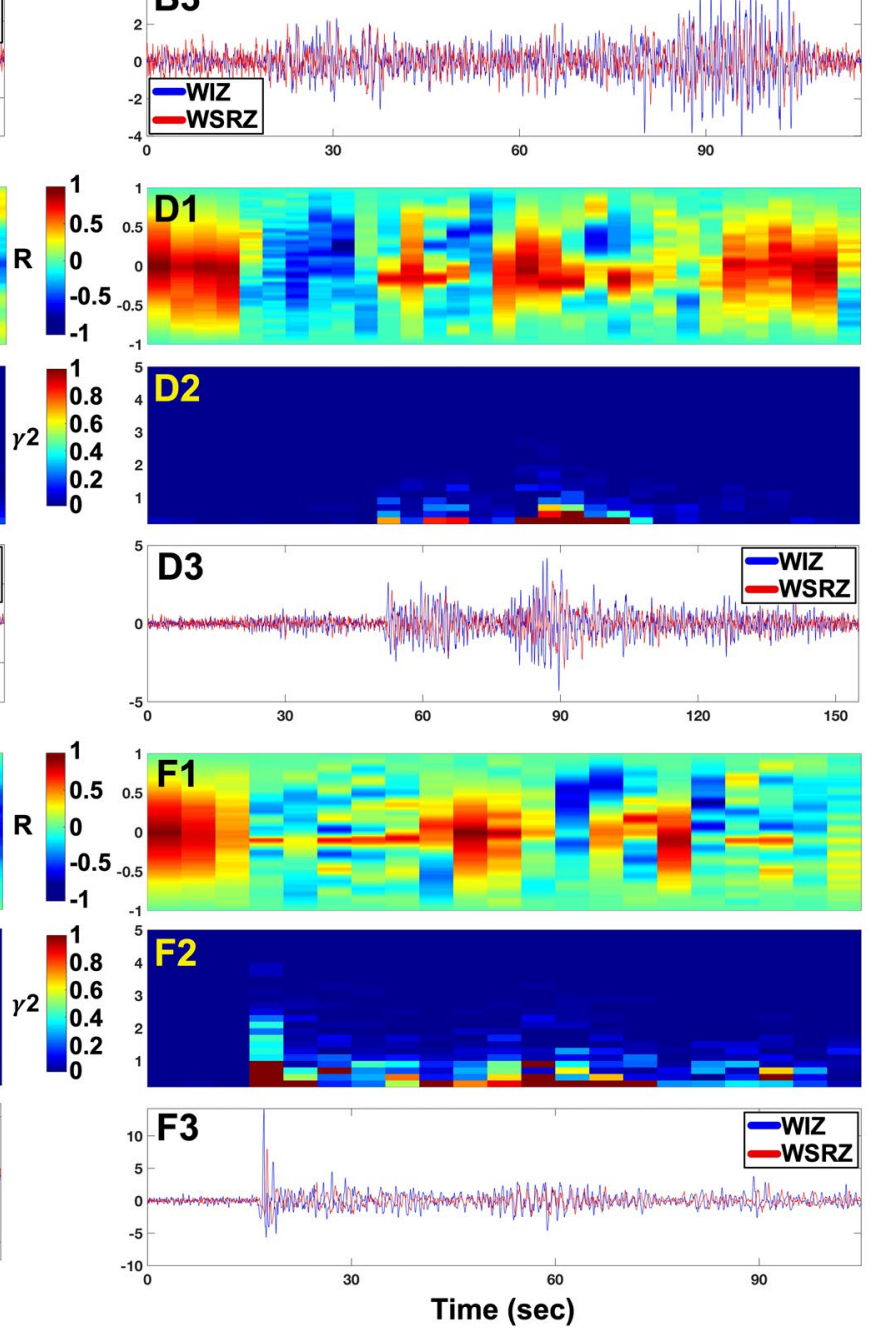

Fig. 10 Acoustic time evolution comparing station WIZ with WSRZ of the 27 April 2016 eruption pulses. A Pulse 1, B pulse 2, C pulse 3, D pulse 4, E pulse 5, F pulse 6. (1) Unfiltered cross-correlation, (2) unfiltered coherence, (3) acoustic signals WIZ and WSRZ overlain filtered between 0.5 and $10 \mathrm{~Hz}$ for each pulse. Subfigures labeled with $1 \mathrm{~s}$ and $2 \mathrm{~s}$ were estimated from 5 -s moving time windows 
low correlation with any time lag value for the interpulse fluctuations (see Fig. 10D, between intra-pulses). Furthermore, comparing Fig. 10 with the spectrograms (Fig. 4), the wavelengths and frequency content within each pulse are variable.

These inconsistencies or migration patterns could be due to many effects. Matoza et al. (2013) noted that high-temperature jet-like gasses that are expelled out of the vents at high velocities, that create jet noise mixing, are highly directional, do not radiate acoustic energy uniformly, and cause an increase in turbulence within the air. These jet noise effects could very well cause the frequency differences within each eruption pulse on Whakaari. Furthermore, the variability in frequency could be caused by near-field effects, resonance in the conduit, overlapping of multiple signals, or multiple eruptions occurring at the same time (Woulff and McGetchin 1976). Another effect on frequency in the acoustic signal can come from scattering due to diffraction of the crater geometry or topography of the ground. Rowell et al. (2014) noted that reverberations from crater walls could cause signal interference and cause timing delays in the data. At Whakaari, the current conduit/vent location is $\sim 10 \mathrm{~m}$ below the main crater floor, and then, there is an extra $300 \mathrm{~m}$ maximum increase in elevation to the crater rim. Any acoustic signal coming from the vent location would not only have to travel out of the eruption crater, but up and over the larger crater rim to reach station WSRZ (Fig. 1). The increased scattering in correlation with lag times is most likely occurring from topographical effects (e.g., McKee et al. 2014). The explanation for the frequency contrasts in the eruptive pulses could also be due to the type of eruption mechanism and will be described later.

\section{Determining eruption pulse characteristics using the volcanic acoustic-seismic ratio}

The volcanic acoustic-seismic ratio (VASR) is the ratio between the acoustic energy and the seismic energy of an eruption or eruption sequence. VASR was first shown by Johnson and Aster (2005) on Karymsky, Russia and Erebus, Antarctica, and later used on Redoubt Volcano, Alaska (McNutt et al. 2013), Te Maari, New Zealand (Jolly et al. 2014a), and at Tungurahua, Ecuador (Palacios et al. 2016). We use VASR on the Whakaari eruption sequence as a means to investigate the partition of energy between the ground and atmosphere to give an idea what the eruption source characteristics might be, as well as, other differences between the multiple pulses (e.g., energy transfer, conduit size, and source area). Johnson and Aster (2005) outlined varying situations for values of VASR, where a low VASR may indicate a large source region, long narrow conduit, and/or a high density plume. Additionally, if the VASR has a high value, the source region may be small, have a short/wide conduit, and/or have a low density plume.

To infer the VASR, both seismic and acoustic energies need to be estimated. To approximate the acoustic energy of an eruption, and assuming that the source is a monopole, the total acoustic energy is depicted by Johnson and Aster (2005) as:

$$
E_{\text {Acoustic }}=\frac{2 \pi r^{2}}{\rho_{\mathrm{A}} c_{\mathrm{A}}} \int \Delta P(t)^{2} \mathrm{~d} t
$$

where $r$ is the source to station distance, $\rho_{\mathrm{A}}$ is the air density, $c_{\mathrm{A}}$ is the air wave velocity, and $\Delta P$ is the excess pressure. For the use at Whakaari, we use a $\rho_{\mathrm{A}}=1.204 \mathrm{~kg} /$ $\mathrm{m}^{3}$ and an air velocity $\left(c_{\mathrm{A}}\right)$ of $340 \mathrm{~m} / \mathrm{s}$. In order to estimate the acoustic energy, many assumptions and caveats must be addressed. First, the assumption of an isotropic radiation pattern is made, but the acoustic output from a volcanic eruption is highly directional, which could introduce errors (Matoza et al. 2013). Additionally, due to the directionality of jet noise, we may have limited angular coverage of the jet noise path from the positioning of the acoustic sensors. Furthermore, dynamics such as moving sources, and parameters like air temperature contrasts, density, conduit geometry, etc., can all have significant effects on the outcome of estimating the energy properly (Matoza et al. 2013).

Estimating the seismic energy of the eruptive pulses in terms of body waves can be shown through Boatwright (1980) and Johnson and Aster (2005) by:

$$
E_{\text {Seismic }}=2 \pi r^{2} \rho c \frac{1}{A} \int S^{2} U(t)^{2} \mathrm{~d} t
$$

where $\rho$ is the density of the ground, $c$ is the seismic medium velocity, $S$ is the site response, $U$ is the seismic amplitude, and $A$ is the wave propagation attenuation that can be determined from $A=e^{(-\pi f r / c Q)}$. Estimating seismic energies, values of $\rho=2120 \mathrm{~kg} / \mathrm{m}^{3}$ and a homogeneous p-wave estimate of $c=2200 \mathrm{~m} / \mathrm{s}$ (Jolly et al. 2017b) were used for Whakaari. Due to possible directional variations among the network array (topography, source directionality of the radiation pattern, site effects, etc.) (e.g., Jolly et al. 2017b), we compare the energies for both acoustic and seismic data for both stations through partitioning (Fig. 11a). The VASR data for both data sets were filtered between 0.5 and $10 \mathrm{~Hz}$ to obtain peak energy content from both sources of data (Figs. 4, 5). The acoustic partitioning (Fig. 11a, circles) between WIZ and WSRZ shows a stable correlation, with station WIZ recording slightly higher energies. As for the seismic energy, the partitioning (Fig. 11a, squares) shows a relatively even energy distribution, but the eruptions tend to have stronger signals for station WSRZ. This could be due a geological medium effect or an effect from the 

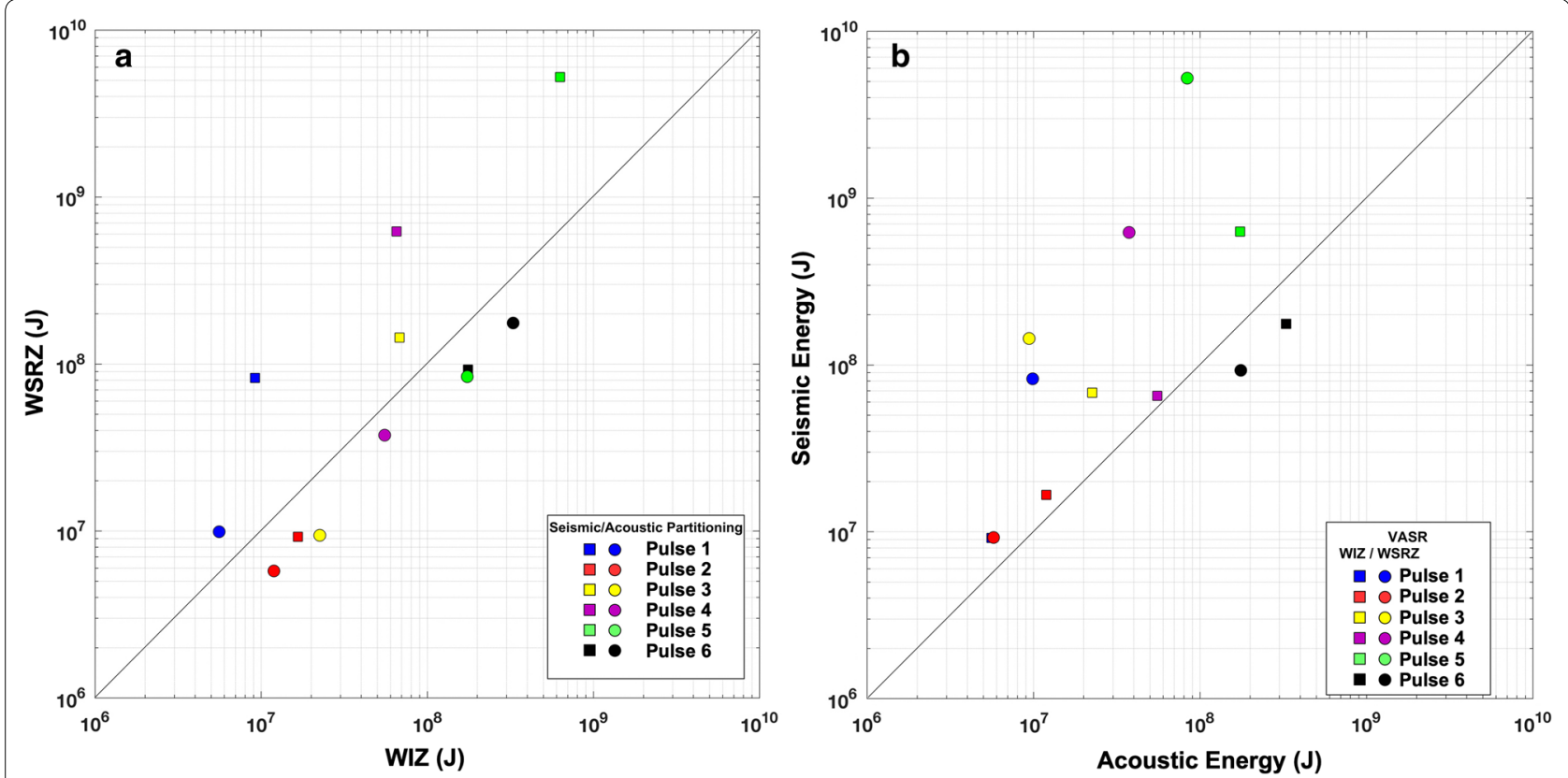

Fig. 11 a Energy partitioning between stations WIZ and WSRZ for acoustic data (circles) and seismic data (squares). b VASRs between stations WIZ (squares) and WSRZ (circles) for all six eruptive pulses. The colors of the points represent the different eruptive pulses. The energies are estimated by computing over the whole length of the eruptive pulse

source radiation directionality of each pulse. Since our signals contain data below $5.0 \mathrm{~Hz}$, we may have near source scattering effects as noted by Takemura et al. (2009). However, we surmise that the variations would be minimal, in the determination for VASR partitioning. Another form of contamination of the data could come from infrasound signals coupling with the ground and being recorded in the seismic data. Even though these data might be present in the signal, we can still proceed due to the fact that ground-coupled airwaves usually have high-frequency content and small energies that only contribute minimally to the overall total energy (Johnson and Aster 2005).

Next, we estimate the ratio of the amount of energy that is transferred through the air compared to the ground by the VASR represented by:

$$
\eta=\frac{E_{\text {Acoustic }}}{E_{\text {Seismic }}}
$$

These values can be exemplified visually by plotting the acoustic and seismic energies for each pulse against each other (Fig. 11b). Station WIZ (Fig. 11b, squares) depicts greater energies for all the pulses, except for pulse 6 , which has higher acoustic energy. Furthermore, for station WSRZ (Fig. 11b, circles) the veer toward the seismic energy is greater than for WIZ. We also note that for both stations pulse 6 is the only eruption to be stronger in acoustic energy than in seismic energy. Additionally, pulse 5 for both sensors has the most seismic energy.

Additionally, due to the variability within each eruptive pulse, we also calculated VASRs with time for each pulse (Fig. 12). Like Fig. 11, Fig. 12 uses seismic and acoustic data filtered between 0.5 and $10 \mathrm{~Hz}$ with the VASR being estimated in 5-s running time windows. When the VASR is greater than 1, the result has stronger acoustic energy, and when the VASR is less than 1, the signal is stronger for the seismic energy. Figure 12 shows a more complex VASR situation than when the ratios were estimated for the entire time period of the eruptive pulse. Within each pulse, the VASR becomes stronger in the acoustic energy or seismic energy and vice versa. This same pattern is also seen in the relationship between the two stations as well, although WIZ has higher ratios most of the time. The varying VASRs could be caused by the same effects as the frequency differences in the pulse signals (Fig. 4). Where site effects or the way/style of eruption could alter the VASR. Furthermore, the differences could be caused simply by impurities in the acoustic signal, in that when the ratio is heavily favored by the seismic energy, the acoustic energy may have been dampened by reflections or noise caused by topography, or jet eddies in the eruption column. In addition to the aforementioned possibilities, the differences in VASRs could be caused by eruption dynamics. The significance of this, as well as the whole eruption setting and process in acoustic and seismic 

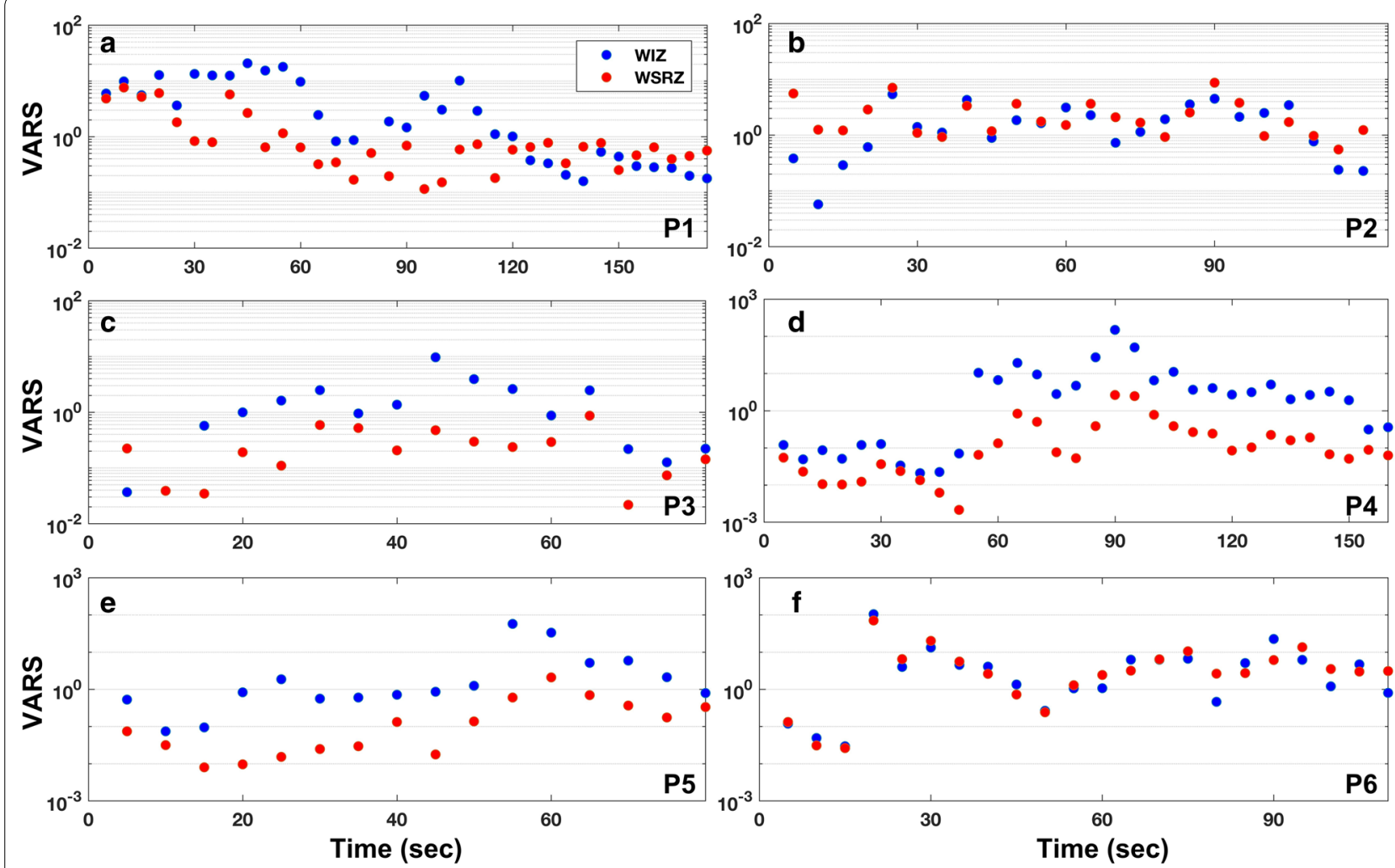

Fig. 12 VASR plots for each of the eruptive pulses with time during the 27 April 2016 eruption. a Pulse 1, b pulse 2, c pulse 3, d pulse 4, e pulse 5, f pulse 6. Blue circles are VASRs for station WIZ, and red circles are VASRs for station WSRZ. 5-s time windows were used to estimate the VASR through time

energy will be discussed in detail below in the discussion section.

\section{Discussion}

The varying frequency levels in the acoustic signals for the 27 April 2016 phreatic eruption on Whakaari could potentially help describe vent characteristics. Garcés and Hansen (1998) noted that changes in frequency might suggest a change in source process or eruption dynamics. The differences in frequency could be explained by changes in the mass flux created by the gas slug in the conduit during the eruption (e.g., Goto et al. 2014). There are two leading theories that combine nicely with the idea of flux changes from differing gas slug characteristics. First, the frequency contrasts could be due to simultaneous explosions (e.g., Ripepe et al. 1993; Taddeucci et al. 2012), where a large gas slug rises up the conduit, explodes creating the large eruption, but then is followed immediately by several smaller bubbles erupting. The second theory uses multiple gas slugs of different sizes moving up the preexisting crack that erupt at regular intervals, which creates the variations in the frequency content of each pulse (Ripepe et al. 1993). For the eruption in April 2016, it is inferred that the eruption dynamics most likely occurred in one of these two ways. On Stromboli, Ripepe et al. (1993) noted that multiple gas burst dynamics produced high seismic frequencies between 5 and $8 \mathrm{~Hz}$. Figure 5 shows the seismic frequency content of the 27 April eruption with peak frequencies between 3 and $10 \mathrm{~Hz}$, suggesting that Whakaari eruption dynamic frequencies may be similar to that of Stromboli.

Additionally, along with the variations in acoustic frequency, there are also variations within each eruptive pulse in phase lag between the two stations (Fig. 10). The phase lag change switching from the two stations could represent eruptive bursts from multiple vents or source locations, or as noted by Matoza et al. (2013) could be jet turbulence excitations or eddies at different altitudes and jet axis angles in the $4.0 \mathrm{~km}$ high eruption column that occurred on Whakaari.

The seismic results show that there could be multiple vents, but at the same time considering the propinquity to each other $(\sim 50 \mathrm{~m})$, the pulses could have easily come from a single vent. Conducting error analysis on the vent location results estimated from ASL, standard bootstrap/ 
Table 2 Summary of error analysis conducted on ASL results

\begin{tabular}{lllllll}
\hline & Pulse 1 & Pulse 2 & Pulse 3 & Pulse 4 & Pulse 5 & Pulse 6 \\
\hline Standard deviation $(\mathrm{m})$ & 78 & 90 & 90 & 79 & 75 & 79 \\
$T$ test $p$ values & $1.1 \times 10^{-6}$ & $8.5 \times 10^{-6}$ & $8.2 \times 10^{-6}$ & $1.5 \times 10^{-6}$ & $1.3 \times 10^{-6}$ & $3.2 \times 10^{-6}$ \\
\hline
\end{tabular}

Table 3 Average delay time between WIZ to WSRZ for each of the six eruption pulses

\begin{tabular}{lllllll}
\hline & Pulse 1 & Pulse 2 & Pulse 3 & Pulse 4 & Pulse 5 & Pulse 6 \\
\hline Delay time (s) & 0.212 & 0.140 & 0.110 & 0.212 & 0.202 & 0.096 \\
\hline
\end{tabular}

jackknife methods (e.g., Quenouille 1949; Tukey 1958) are used. Following the procedure shown by Walsh et al. (2017), we recalculate the vent locations for each pulse using every 6,5 , and 4 station combinations. The standard deviations for vent location for each pulse are listed in Table 2. From the error analysis, each pulse vent can be located with an uncertainty on average of less than $80 \mathrm{~m}$ from the six station configuration result. This indicates that the error analysis cannot uniquely constrain which vent the pulse may have come from.

To test whether the uncertainties in the error analysis for the ASL results can be trusted, we next conduct a one-sample $t$ test. One-sample $t$ tests (e.g., Ross and Willson 2017) can help to infer whether the ASL results are real or if a result is randomized. $T$ tests are used to calculate $\mathrm{t}$ values, which then can be compared to a known critical $t$ value to determine if the null hypothesis is accepted (not random) or rejected (random). In order to determine if the null hypothesis is accepted or rejected, a $p$ value must be determined and set. In most cases, the $p$ value is often set at $5 \%$ or 0.05 , stating that if the $p$ value is greater than $5 \%$ then the null hypothesis is rejected, and the ASL results could have occurred by chance. Conversely, if the $p<0.05$ then the locations are not random and there is no statistically significant difference between the ASL results, and the null hypothesis is accepted. Table 2 lists the $p$ values of the $t$ test for each of the six eruptive pulses, showing that in each case the null hypothesis is accepted. This indicates that even though the pulses on average have an uncertainty of $\sim 80 \mathrm{~m}$, the bootstrap/jackknife ASL results are not random and could be real.

Analyzing the acoustic data shows that when the signals are highly correlated, the phase lag between the two stations is $\sim-0.25$ to $0.25 \mathrm{~s}$ (Fig. 10), indicating that the eruption could have come from an area of multiple vents. To further analyze the difference in time offsets, we calculate the average delay time from WIZ to WSRZ (Table 3) for each of the eruption pulses. The average

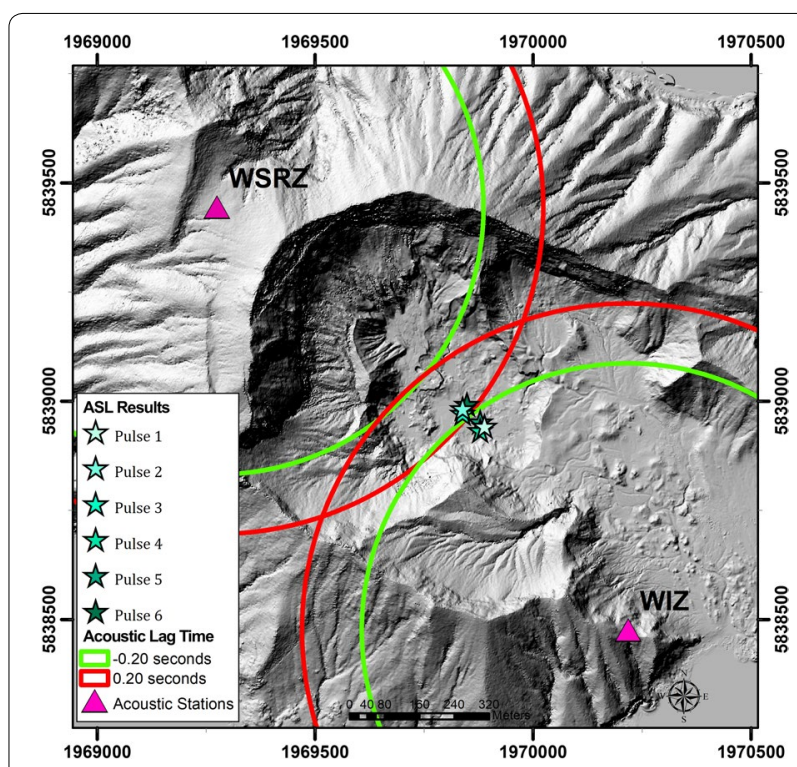

Fig. 13 Map projection of Whakaari showing the acoustic lag time range ( -0.20 to $0.20 \mathrm{~s}$ ) from the acoustic data projected as distance radii from each station. Acoustic lag times at an air velocity of $340 \mathrm{~m} / \mathrm{s}$ equate to a distance range between $611 \mathrm{~m}$ (green circles) and $748 \mathrm{~m}$ (red circles) away from each station. The calibrated ASL results for each eruption pulse from Fig. 8 are also plotted as green stars

delay time estimations suggest that pulses 1,4 , and 5 and pulses 2, 3, and 6 have similar delay times. These groupings of pulse number are the same as for the ASL results. To better constrain the delay times in terms of distance, Fig. 13 shows the map projection of what a -0.20 (green circle) to 0.20 (red circle) second lag time would indicate in terms of distance from the two acoustic stations, along with the estimated ASL results (green stars). The circles in Fig. 13 are calculated based on a uniform radiation pattern and airwave velocity of $340 \mathrm{~m} / \mathrm{s}$. Estimating the distance from each station, a -0.20 to $0.20 \mathrm{~s}$ time lag equates to distance difference of $\sim 68 \mathrm{~m}$, or a radii from each station between 611 and $748 \mathrm{~m}$. Pulses 1, 4, and 5 
are within the $-0.20 \mathrm{~s}$ circle for WIZ, whereas pulses 2 , 3 , and 6 are between the $-0.20 \mathrm{~s}$ radius for WIZ and the $0.20 \mathrm{~s}$ radius for WSRZ. If we trust the six station calibrated ASL results, this would indicate that pulses 1, 4, and 5 would have to be at least at a $-0.20 \mathrm{~s} \mathrm{lag}$, and that pulses 2,3 , and 6 could be anywhere between -0.20 and $0.20 \mathrm{~s}$ radius from WIZ. This indication of two vents can be seen in the average delay time estimations on Table 3, as well as, shown by pulses 1,4 , and 5 all having delay times greater than $0.20 \mathrm{~s}$, while pulses 2,3 , and 6 do not.

To explore eruption dynamics, we looked at the partitioning between the acoustic and seismic energies for each eruptive pulse. A VASR value can mean many different things in terms of the eruptive process. Johnson and Aster (2005) have detailed four different possibilities for a high or low VASR. A low VASR could mean a large source region, a deep source, high density plume, or a high impedance lava lake and vice versa for a high VASR. Looking at the VASR values for the 27 April eruption and averaging both recording stations, pulses $1,3,4$, and 5 have low VASR values compared to pulses 2 and 6 . Considering just the most energetic eruptions, this could very well mean that pulses 4 and 5 came from a deeper source region than pulse 6 . We favor the theory of depth differences in terms of VASR difference, because the seismic signals (Fig. 2) show pulses 1, 3, 4, and 5 with distinct heightened traces compared to the signals of the other eruptive pulses, and due to the fact that the difference between the seismic and acoustic energies from eruptions commonly correlates to the depth of the source (Ichihara 2016).

\section{Conclusions}

At approximately 09:36 UTC on 27 April 2016, a phreatic eruption occurred on Whakaari Island producing six major eruptive pulses. Seismic and acoustic data were collected, and eruption characteristics were deduced. The acoustic data had varying frequency content inferring eruption dynamics of either a large gas slug followed by smaller gas bubbles or multiple gas bubbles bursting at different time intervals. Eruption vent locations were estimated through the use of ASL with the seismic data. Vent locations for the eruptive pulses were found to have either come from a single vent or possibly from two different locations (albeit in very close proximity), where pulses 1,4 , and 5 and pulses 2, 3, and 6 originated from the same vent. These pairings compare favorably with the VASR analysis conducted to explore eruption dynamics, as well as lag time analysis for the acoustic data. The VASR analysis showed that pulse 5 contained more seismic energy, and that pulse 6 had stronger acoustic strength then the rest of the pulses. This suggests that pulse 5 came from a deeper source location than pulse
6. In conclusion, due to error analysis and acoustic phase lags varying with frequency and eruption pulse duration, we cannot say for certain that the eruptive pulses came from one or multiple vents. Each scenario is equally as possible, but due to the combination of the six station ASL results and the acoustic delay time analysis (Fig. 13), we favor the two vent theory where pulses 1,4 , and 5 and pulses 2,3 , and 6 erupted from the same vent.

\section{Abbreviations \\ GNS: Geological and Nuclear Sciences; VT: volcano-tectonic; LP: long-period; VLP: very long-period; ASL: amplitude source location; VASR: volcanic acous- tic-seismic ratio.}

\section{Authors' contributions}

BW preformed ASL, acoustic, and VASR analysis, and drafted the manuscript. All participating authors contributed to the discussions and editing of the draft of the manuscript as well as approving the final edition. All authors read and approved the final manuscript.

\section{Author details \\ ${ }^{1}$ Volcanic Risk Solutions, Institute of Agriculture and Environment, Massey University, Private Bag 11 222, Palmerston North 4442, New Zealand. ${ }^{2}$ School of Earth Sciences, University College Dublin, Belfield, Dublin 4, Ireland. ${ }^{3}$ Insti- tute of Geophysics, Czech Academy of Science, Prague, Czech Republic. ${ }^{4}$ GNS Science, 1 Fairway Drive, Avalon, Lower Hutt 5010, New Zealand.}

\section{Acknowledgements}

The seismic data were collected from the Earthquake Commission (EQC) that funded the GeoNet project. A special thanks to Cameron Asher for creating a new post-eruption digital elevation map for Whakaari, as well as C. Lormand and S. Lee for extra support.

\section{Competing interests}

The authors declare that they have no competing interests.

Availability of data and materials

The data used in this manuscript can be accessed from the GeoNet website at www.geonet.org.nz.

Consent for publication

Not applicable.

Ethics approval and consent to participate

Not applicable.

\section{Funding}

This paper was funded by the Massey University Dissemination Grant.

\section{Publisher's Note}

Springer Nature remains neutral with regard to jurisdictional claims in published maps and institutional affiliations.

Received: 3 April 2018 Accepted: 17 February 2019

Published online: 28 February 2019

\section{References}

Aki K, Ferrazzini V (2000) Seismic monitoring and modeling of an active volcano for prediction. J Geophys Res 105:16617-16640

Almendros J, Chouet B (2003) Performance of the radial semblance method for the location of very long period volcanic signals. Bull Seismol Soc Am 93:1890-1903 
Aspinall W, Miller A, Lynch L, Latchman J, Stewart R, White R, Power J (1998) Soufriere Hills eruption, Montserrat, 1995-1997: volcanic earthquake locations and fault plane solutions. GRL 25:3397-3400

Battaglia J, Aki K (2003) Location of seismic events and eruptive fissures on the Piton de la Fournaise volcano using seismic amplitudes. J Geophys Res. https://doi.org/10.1029/2002JB002193

Boatwright J (1980) A spectral theory for circular seismic sources; simple estimations of source dimension, dynamic stress drop, and radiated seismic energy. BSSA 70:1-27

Chouet B, Saccorotti G, Dawson P, Martini M, Scarpa R, Luca G, Milana G, Cattaneo M (1999) Broadband measurements of the sources of explosions at Stromboli Volcano, Italy. Geophys Res Lett 26:1937-1940

Chouet B, Dawson P, James M, Lane S (2010) Seismic source mechanism of degassing bursts at Kilauea Volcano, Hawaii: Results from waveform inversion in the 10-50 s band. J Geophys Res 115:B09311

Christenson B, White S, Britten K, Scott B (2017) Hydrological evolution and chemical structure of a hyper-acidic spring-lake system on Whakaari/ White Island, NZ. J Volcanol Geotherm Res 346:180-211

Cole J, Thordarson T, Burt R (2000) Magma origin and evolution of White Island (Whakaari) Volcano, Bay of Plenty, New Zealand. J Petrol 41:867-895

Garcés M, Hansen R (1998) Wavefrom analysis of seismoacoustic signals radiated during the Fall 1996 eruption of Pavlof volcano, Alaska. Geophys Res Lett 25:1051-1054

Garcés M, McNutt S (1997) Theory of the airborne sound field generated in a resonant magma conduit. J Volcanol Geotherm Res 78:155-178

Garcés M, Harris A, Hetzer C, Johnson J, Rowland S (2003) Infrasonic tremor observed at Kilauea Volcano, Hawai'l. Geophys Res Lett. https://doi. org/10.1029/2003gl018038

Goto A, Ripepe M, Lacanna G (2014) Wideband acoustic records of explosive volcanic eruptions at Stromboli: new insights on the explosive process and the acoustic source. Geophys Res Lett 41:3851-3857

Hamling I (2017) Crater lake controls on volcano stability: insights from White Island, New Zeeland. Geophys Res Lett. https://doi.org/10.1002/2017G L075572

Heap M, Kennedy B, Pernin N, Jacquemard L, Baud P, Farquharson J, Scheu B, Lavallee Y, Gilg A, Brake M, Mayer K, Jolly A, Reuschle T, Dingwell D (2015) Mechanical behavior and failure modes in the Whakaari (White Island Volcano) hydrothermal system, New Zealand. J Volcanol Geotherm Res 295:26-42

Houghton B, Nairn I (1991) The 1976-1982 Strombolian and phreatomagmatic eruptions of White Island, New Zealand: eruptive and depositional mechanisms at a "wet" volcano. Bull Volcanol 54:25-49

Ichihara M (2016) Seismic and infrasonic eruption tremors and their relation to magma discharge rate: a case study for sub-Plinian events in the 2011 eruption of Shinmoe-dake, Japan. J Geophys Res Solid Earth 121:7101-7118

Ichihara M, Takeo M, Yokoo A, Oikawa J, Ohminato T (2012) Monitoring volcanic activity using correlation patterns between infrasound and ground motion. Geophys Res Lett 39:L04304

Ishii M (2011) High-frequency rupture properties of the $M_{w} 9.0$ off the Pacific coast of Tohoku Earthquake. Earth Planets Space 63:609-614

Ishii M, Shearer P, Houston H, Vidale J (2005) Extend, duration and speed of the 2004 Sumatra-Andaman earthquake imaged by the Hi-Net array. Nature 435:16

Ishii M, Shearer P, Houston H, Vidale J (2007) Teleseismic P-wave imaging of the 26 December 2004 Sumatra-Andaman and 28 March 2005 Sumatra earthquake ruptures using the Hi-Net array. J Geophys Res 112:B1 1307

Johnson JB (2003) Generation and propagation of infrasonic airwaves from volcanic explosions. J Volcanol Geotherm Res 121:1-14

Johnson JB, Aster R (2005) Relative partitioning of acoustic and seismic energy during Strombolian eruptions. J Volcanol Geotherm Res 148:334-354

Johnson JB, Lees J, Yepes H (2006) Volcanic eruptions, lightning, and a waterfall: differentiating the menagerie of infrasound in the Ecuadorian jungle. Geophys Res Lett. https://doi.org/10.1029/2005GL025515

Jolly A, Chardot L, Neuberg J, Fournier N, Scott B, Sherburn S (2012) High impact mass drops from helicopter: a new active seismic source method applied in an active volcanic setting. Geophys Res Lett 39:L12306. https:// doi.org/10.1029/2012gl051880

Jolly A, Jousset P, Lyons J, Carniel R, Fournier N, Fry B, Miller C (2014a) Seismoacoustic evidence for an avalanche driven phreatic eruption through a beheaded hydrothermal system: an example from the 2012 Tongariro eruption. J Volcanol Geotherm Res 286:331-347

Jolly A, Lokmer I, Kennedy B, Key H, Procter J, Lyons J, Jolly G (2014b) Active seismic sources as a proxy for seismic surface processes: an example from the 2012 Tongariro volcanic eruptions, New Zealand. J Volcanol Geotherm Res 286:317-330

Jolly A, Kennedy B, Edwards M, Jousset P, Scheu B (2016) Infrasound tremor from bubble burst eruptions in the viscous shallow crater lake of White Island, New Zealand, and its implications for interpreting volcanic source processes. J Volcanol Geotherm Res 327:585-603

Jolly A, Lokmer I, Thun J, Salichon J, Fry B, Chardot L (2017a) Insights into fluid transport mechanisms at White Island from analysis of coupled very long-period (VLP), long-period (LP) and high-frequency (HF) earthquakes. J Volcanol Geotherm Res 343:75-94

Jolly AD, Matoza RS, Fee D, Kennedy BM, lezzi AM, Fitzgerald RH, Austin AC, Johnson R (2017b) Capturing the acoustic radiation pattern of Strombolian eruptions using infrasound sensors aboard a tethered aerostat, Yasur Volcano, Vanuatu. Geophys Res Lett 44(19):9672-9680

Jones K, Johnson J, Aster R, Kyle P, McIntosh W (2008) Infrasonic tracking of large bubble bursts and ash venting at Erebus Volcano, Antarctica. J Volcanol Geotherm Res 177:661-672

Kanamori H (1993) Locating earthquakes with amplitude: application to realtime seismology. Bull Seismol Soc Am 83:264-268

Kawakatsu H, Kaneshima S, Matsubayashi H, Ohminato T, Sudo Y, Tsutsui T, Uhira K, Yamasato H, Ito H, Legrand D (2000) Aso94: Aso seismic observation with broadband instruments. J Volcanol Geotherm Res 101:129-145

Kilgour G, Kennedy B, McSporran A, Farquhar A, Wilson T, Gates S (2019) Phreatic eruption dynamics derived from deposit analysis: a case study from a small, phreatic eruption from Whakaari/White Island. Earth Planets Space, New Zealand. https://doi.org/10.1186/s40623-019-1008-8

Kumagai H, Palacios P, Maeda T, Castillo D, Nakano M (2009) Seismic tracking of lahars using tremor signals. J Volcanol Geotherm Res 183:112-121

Kumagai H, Palacio P, Ruiz M, Yepes H, Kozono T (2011) Ascending seismic source during an explosive eruption at Tungurahua volcano, Ecuador. Geophys Res Lett 38:L01306

Kumagai K, Lacson R, Maeda Y, Figueroa M, Yanashina T, Ruiz M, Palacios P, Ortiz H, Yeps H (2013) Source amplitudes of volcano-seismic signals determined by the amplitude source location method as a quantitative measure of event size. J Volcanol Geotherm Res 257:57-71

Kumagai H, Mothes P, Ruiz M, Maeda Y (2015) An approach to source characterization of tremor signals associated with eruptions and lahars. Earth Planets Space 67:178. https://doi.org/10.1186/s40623-015-0349-1

Lahr J (1989) HYPOELLIPSE/version 2.0: a computer program for determining local earthquake hypocentral parameters, magnitudes, and first motion pattern. U.S. Geological Survey, Open-File 89-116

Lahr J, Chouet B, Stephens C, Power J, Page R (1994) Earthquake classification, location, and error analysis in a volcanic environment: implications for the magmatic system of the 1989-1990 eruptions at Redoubt Volcano, Alaska. J Volcanol Geotherm Res 62:137-151

Lee WHK, Bennett RE, Meagher L (1972) A method for estimating magnitude of local earthquakes from signal duration. Open file report, USGS

Matoza R, Fee D (2014) Infrasonic component of volcano-seismic eruption tremor. Geophys Res Lett 41:1964-1970

Matoza R, Fee D, Neilsen T, Gee K, Ogden D (2013) Aeroacoustics of volcanic jets: acoustic power estimation and jet velocity dependence. J Geophys Res 118:1-16

Mayer K, Scheu B, Gilg A, Heap M, Kennedy B, Lavallee Y, Brake M, Dingwell $D$ (2015) Experimental constraints on phreatic eruption processes at Whakaari (White Island volcano). J Volcanol Geotherm Res 302:150-162

McKee K, Fee D, Rowell C, Yokoo A (2014) Network-based evaluation of the infrasonic source location at Sakurajima Volcano, Japan. Seismol Res Lett 85:1200-1211

McNutt S, Thompson M, West M, Fee D, Stihler S, Clark E (2013) Local seismic and infrasound observations of the 2009 explosive eruptions of Redoubt Volcano, Alaska. J Volcanol Geotherm Res 259:63-76

Neidel N, Tarner MT (1971) Semblance and other coherency measure for multichannel data. Geophysics 36:483-497

Nishi Y, Sherburn S, Scott B, Sugihara M (1996) High-frequency earthquakes at White Island Volcano, New Zealand: insights into the shallow structure of a volcano-hydrothermal system. J Volcanol Geotherm Res 72:183-197 
Nishimura T, Nakamichi H, Tanaka S, Sato M, Kobayashi T, Ueki S, Hamaguchi $\mathrm{H}$, Ohtake M, Sato H (2000) Source process of very long period seismic events associated with the 1998 activity of Iwate Volcano, northeastern Japan. GRL 105:19135-19147

Ogiso M, Yomogida K (2015) Estimation of locations and migration of debris flows on Izu-Oshima Island, Japan, on 16 October 2013 by the distribution of high frequency seismic amplitudes. J Volcanol Geotherm Res 298:15-26

Ogiso M, Matsubayashi H, Yamamoto T (2015) Descent of tremor source locations before the 2014 phreatic eruption of Ontake Volcano, Japan. Earth Planets Space 67:206. https://doi.org/10.1186/s40623-015-0376-y

Palacios P, Diez M, Kendall J, Mader H (2016) Seismic-acoustic energy partitioning during a paroxysmal eruptive phase of Tungurahua volcano, Ecuador. Geophys J Int 205:1900-1915

Quenouille MH (1949) Approximate tests of correlation in time-series. J R Stat Soc B 11:68-84

Ripepe M, Marchetti E (2002) Array tracking of infrasonic sources at Stromboli Volcano. Geophys Res Lett 29:22

Ripepe M, Rossi M, Saccorotti G (1993) Image processing of explosive activity at Stromboli. J Volcanol Geotherm Res 54:335-351

Ross A, Willson VL (2017) One-sample T-test. In: Basis and advanced statistical tests. Sense Publishers, Rotterdam, pp 1-9

Rowell C, Fee D, Szuberla C, Arnoult K, Matoza R, Firstov P, Kim K, Makhmudov E (2014) Three-dimensional volcano-acoustic source localization at Karymsky Volcano, Kamchatka, Russia. J Volcanol Geotherm Res 283:101-115

Sherburn S, Scott B (1993) B-type volcanic earthquakes at White Island Volcano, New Zealand. J Volcanol Geotherm Res 56:351-355

Sherburn S, Scott B, Hurst A (1991) Volcanic tremor and activity at White Island, New Zealand, July-September 1991. NZ J Geol Geophys 39(2):329-332

Sherburn S, Scott B, Nishi Y, Sugihara M (1998) Seismicity at White Island volcano, New Zealand: a revised classification and inferences about source mechanism. J Volcanol Geotherm Res 83:287-312
Taddeucci J, Ibarguengoitia A, Moroni M, Tometta L, Capponi A, Scarlato P, Dingwell D, De Rita D (2012) Physical parameterization of Strombolian eruptions via experimentally-validated modeling of high-speed observations. Geophys Res Lett 39:L16306

Taisne B, Brenguier F, Shapiro N, Ferrazzini V (2011) Imaging the dynamics of magma propagation using radiated seismic intensity. Geophys Res Lett 38:L04304

Takemura S, Furumura T, Saito T (2009) Distortion of the apparent S-wave radiation pattern in the high-frequency wavefield: Tottori-Ken Seibu, Japan, earthquake of 2000. Geophys J Int 178:950-961

Tukey JW (1958) Bias and confidence in not-quite large samples (abstract). Ann Math Stat 29:614

Vergniolle S, Brandeis G (1994) Origin of the sound generated by Strombolian explosions. Geophys Res Lett 21:1959-1962

Walsh B, Jolly A, Procter J (2016) Seismic analysis of the 13 October 2012 Te Maari, New Zealand, lake breakout lahar: insights into flow dynamics and the implications on mass flow monitoring. J Volcanol Geotherm Res 324:144-155

Walsh B, Jolly A, Procter J (2017) Calibrating the amplitude source location (ASL) method by using active seismic sources: an example from Te Maari volcano, Tongariro National Park, New Zealand. Geophys Res Lett. https:// doi.org/10.1002/2017gl073000

Walter F, Burtin A, McArdell B, Hovius N, Weder B, Turowski J (2017) Testing seismic amplitude source location for fast debris-flow detection at Illgraben, Switzerland. Nat Hazards Earth Syst Sci 17:939-955

Werner C, Hurst T, Scott B, Sherburn S, Christenson B, Britten K, Baker J, Mullan B (2008) Variability of passive gas emissions, seismicity, and deformation during crater lake growth at White Island Volcano, New Zealand 2002-2006. J Geophys Res 113:B01204

Woulff G, McGetchin T (1976) Acoustic noise from volcanoes: theory and experiment. Geophys J R Astron Soc 45:601-616

Yamasato H (1997) Quantitative analysis of pyroclastic flows using infrasonic and seismic data at Unzen Volcano, Japan. J Phys Earth 45:397-416

\section{Submit your manuscript to a SpringerOpen ${ }^{\circ}$ journal and benefit from:}

- Convenient online submission

- Rigorous peer review

- Open access: articles freely available online

- High visibility within the field

- Retaining the copyright to your article

Submit your next manuscript at $\boldsymbol{\nabla}$ springeropen.com 